\title{
Operational Strategy and Planning for Raw Natural Gas Refining Complexes: Process Modeling and Global Optimization \\ Dol:
}

10.1002/aic.15416

\section{Document Version}

Accepted author manuscript

Link to publication record in Manchester Research Explorer

Citation for published version (APA):

Zhang, B. J., Chen , Q. L., Li, J., \& Floudas, C. A. (2016). Operational Strategy and Planning for Raw Natural Gas Refining Complexes: Process Modeling and Global Optimization. AlChE Journal. https://doi.org/10.1002/aic.15416

\section{Published in:}

AIChE Journal

\section{Citing this paper}

Please note that where the full-text provided on Manchester Research Explorer is the Author Accepted Manuscript or Proof version this may differ from the final Published version. If citing, it is advised that you check and use the publisher's definitive version.

\section{General rights}

Copyright and moral rights for the publications made accessible in the Research Explorer are retained by the authors and/or other copyright owners and it is a condition of accessing publications that users recognise and abide by the legal requirements associated with these rights.

\section{Takedown policy}

If you believe that this document breaches copyright please refer to the University of Manchester's Takedown Procedures [http://man.ac.uk/04Y6Bo] or contact uml.scholarlycommunications@manchester.ac.uk providing relevant details, so we can investigate your claim.

\section{OPEN ACCESS}




\title{
Operational Strategy and Planning for Raw Natural
}

\section{Gas Refining Complexes: Process Modeling and}

\section{Global Optimization}

\author{
B. J. Zhang and Q. L. Chen
}

School of Chemical Engineering and Technology, Guangdong Engineering Technology Research Center for Petrochemical Energy Conservation, Key Lab of Low-carbon Chemistry \& Energy Conservation of Guangdong Province, Sun Yat-Sen University, No. 135, Xingang West Road, Guangzhou, 510275, China

Jie Li $i^{\ddagger}$ and C. A. Floudas

Artie McFerrin Department of Chemical Engineering, Texas A\&M University, 3122 TAMU, College Station, TX 77843 , USA

Texas A\&M Energy Institute, Texas A\&M University, 3372 TAMU, College Station, TX 77843, USA

\section{ABSTRACT}

Optimal operational strategy and planning of a raw natural gas refining complex (RNGRC) is very challenging since it involves highly nonlinear processes, complex thermodynamics, blending, and utility systems. In this paper, we first propose a superstructure integrating a utility system for the RNGRC, involving multiple gas feedstocks and different product specifications. Then, we develop a large-scale nonconvex mixed-integer nonlinear programming (MINLP) optimization model. The model incorporates rigorous process models for input and output relations based on fundamentals of thermodynamics and unit operations and accurate models for utility systems. To reduce the noncovex items in the proposed MINLP model, equivalent reformulation techniques are introduced.

\footnotetext{
${ }^{\ddagger}$ Current address: School of Chemical Engineering and Analytical Science, The University of Manchester, Manchester, M139PL UK.

Correspondence concerning this article should be addressed to B. J. Zhang at zhbingj@mail.sysu.edu.cn and C. A. Floudas at floudas@tamu.edu.
}

This article has been accepted for publication and undergone full peer review but has not been through the copyediting, typesetting, pagination and proofreading process which may lead to differences between this version and the Version of Record. Please cite this article as doi: 10.1002/aic.15416

(C) 2016 American Institute of Chemical Engineers (AIChE)

Received: Mar 29, 2016; Revised: Jun 10, 2016; Accepted: Jul 06, 2016

This article is protected by copyright. All rights reserved. 
Finally, the reformulated nonconvex MINLP model is solved to global optimality using state of the art deterministic global optimization approaches. The computational results demonstrate that a significant profit increase is achieved using the proposed approach compared to that from the real operation.

\section{Introduction}

Nowadays, energy plays a prominent role in improving people's life quality and promoting economic development. Prior to the breakthrough of an alternative clean and renewable energy technology, the carbon-heavy fossil fuels are still the main sources to meet energy demand. ${ }^{1,2}$ Among the carbon-heavy fossil fuels, coal is the dirtiest, while natural gas is the cleanest with significant reserves. ${ }^{1,3}$ As a result, the demand of natural gas as a primary energy source is sharply increasing in the last decades. For example, China, facing grand challenges of environmental protection and greenhouse gas reduction, is forced to change configurations of primary energy sources. Natural gas is forced to increase from $4 \%$ to $10 \%$ before $2020 .{ }^{4}$ Raw natural gas from wells or fields has to be processed before it enters downstream users because of strict restrictions on gas specifications from downstream customers. Therefore, RNGRCs are widely built and expanded to increase the production of natural gas and at the same time provide qualified gas specifications for downstream customers.

A RNGRC is highly complicated and energy intensive. It involves many nonlinear processes such as $\mathrm{CO}_{2}$ treating processes, dew point control processes, distillation, and gas compression processes. Planning of such RNGRC involves several operations such as production operations, blending, and utilities operations. Optimal planning of a RNGRC has several advantages such as profit increase, cost reduction, energy savings, and improvement of customer satisfactions, etc. Planning such complex system based on the operator's experiences and heuristics may lead to costly production and energy inefficiency. Thus, optimal planning through advanced techniques of MINLP offers significant opportunities for cost reductions and energy savings. 
The optimization using advanced techniques in natural gas industry has received much attention during the last decades, ${ }^{10}$ similar to other sectors such as petroleum industry, pharmaceuticals, food industries and batch processes. ${ }^{1,5,6}$ Most of those contributions in natural gas industry are limited to the optimization of natural gas productions (recovery), gas pipeline network, and gas market problems. For instance, Diaz et al. ${ }^{11}$ proposed a turbo-expansion process model and integrated it into the MINLP optimization problem to optimize the design and debottlenecking of natural gas processing plants. Variable compositions of natural gas were investigated to determine the optimal plant topology and operating parameters under different process conditions. Selot et al. ${ }^{12}$ studied the model of transportation pipeline and compressors, and combined them into a short-term operational planning model to optimize the natural gas production system, and applied it to the Sarawak production system in East Malaysia. The uncertainty related with product quality in the proposed natural gas production network was addressed later by Li et al. ${ }^{13}$ Tabkhi et al. ${ }^{14}$ investigated the models of pipelines and compressors for long distance transportation of gas, and used these models to minimize fuel consumption in the compression station. Flores-Salazar et al. ${ }^{15}$ presented a multi-period mathematical model for gas and oil production systems on the basis of two conceptual process units (well and manifold). The total production cost is simplified as a result of a cost coefficient multiplied by the capacity of well. Recently, design of natural gas to liquid production system was also investigated via mathematical optimization and integration of processes, power, heat and utilities. ${ }^{16,17}$ These publications focus more on raw natural gas exploiting and transporting. The process models are mainly focused on compressors and long distance pipelines, and less on raw natural gas refining processes. Nevertheless, RNGRCs have energy-intensive processes, such as dew point controllers, $\mathrm{CO}_{2}$ treating and liquid separations. The material and energy models of these processes are further investigated in this study.

Shale gas, an abnormal natural gas, has a similar production system and network with normal natural gas. Many mathematical models and optimization approaches have been proposed for design, synthesis, integration and optimization of shale gas production systems. ${ }^{2}$ Most of them 
mainly focused on shale gas supply chain network design and optimization. For instance, Cafaro and Grossmann ${ }^{18}$ developed a large-scale MINLP model for strategic planning and design of a shale gas supply chain network. The nonlinearities mainly come from the accurate calculation of equipment cost. A two-level branch-and-refine procedure incorporating a piecewise linear approximation scheme was proposed to solve the model to global optimality. Gao and You ${ }^{19}$ formulated a multi-objective nonconvex MINLP model for design and operational planning of a shale gas supply chain network integrating the well-to-wire life cycle of electricity generated from shale gas, and used the Pareto-optimal frontier to investigate the trade-off between economic and environmental objectives. Meanwhile, they also considered the water management in shale gas supply chain. ${ }^{20}$ These works contributed to the optimization for the field and well distribution of shale gas exploration, and the network between shale gas wells and customers. They focused on the high level of network, and less on refining processes and utilities. In this study, the models for raw natural gas refining processes and the integration of processes and utility systems are investigated to optimize the operation of RNGRCs.

To the best of our knowledge, very few efforts have been attempted for the planning problem of raw natural gas refining processes. In this paper, the operational planning problem of raw natural gas refining processes is addressed using advanced techniques of MINLP. Thermodynamic models are employed as a basis for the development of rigorous process models including mass balances, input and output relations, and energy requirements. The model for the utility system is also developed to calculate total utilities that are required in a RNGRC. Based on this, the entire planning model is formulated as a large-scale non-convex MINLP optimization model. The non-conyex nonlinearities mainly arise from the mathematical modeling of thermodynamics. The state-of-the-art deterministic global optimization approaches are used to solve the proposed model to global optimality. The computational results indicate that a significant profit increase of $10.21 \%$ is achieved using the advanced optimization techniques compared to that from real operations. 


\section{Problem Statement}

\section{Process description}

A typical RNGRC is illustrated in Figure 1 . There are $U(u=1,2,3, \ldots, U)$ processes and $S(s=$ $1,2,3, \ldots, S)$ streams. The RNGRC receives raw natural gas from several parallel terminals, which varies in chemical compositions, pressures, and $\mathrm{CO}_{2}$ contents. The gas terminals are denoted as $\mathrm{RNG}_{u}$. Total $C(c=1,2,3, \ldots, C)$ components are assumed in the raw natural gas. Chemical composition and pressure of raw natural gas from different gas terminals vary. A RNGRC has to process several kinds of raw natural gas simultaneously. Hence, how to blend and refine multiple raw natural gas can play a significant role. $\mathrm{CO}_{2}$ is a major impurity in raw natural gas. $\mathrm{CO}_{2}$ contents in raw natural gas from different fields or wells vary in a relatively large range. Multiple raw natural gas streams with different hydrocarbon and $\mathrm{CO}_{2}$ contents are considered in this study.

Several parallel and interconnected refining processes are installed to simultaneously process different types of raw natural gas. The processes $U$ includes plug catchers, dew point controllers, $\mathrm{CO}_{2}$ treating, dehydration, compressors, separators, deethanizers, and stabilizers. Note that $\mathrm{CO}_{2}$ treating process includes an absorber and a regenerator. Any plug catcher belonging to refining processes $U$ is denoted as $\mathrm{PCD}_{u}$. Similarly, any dew point controller, $\mathrm{CO}_{2}$ treating process, compression, separator, deethanizer, and stabilizer in refining processes $U$ are denoted as $D P C_{u}$, $D C P_{u}, C O M_{u}, S E P_{u}, D E E_{u}$ and $S T A_{u}$, respectively.

Final products including different grades of natural gas, liquid petroleum gas (LPG), and naphtha are provided from the RNGRC. Different grades of natural gas from refining processes are mixed together in the pipeline to meet the minimum pressure requirement $\left(\rho_{u}\right)$ and the maximum impurity tolerance $\left(v_{u, c}\right)$ of downstream customers, which is denoted as $\mathrm{CUS}_{u}$. The final natural gas products that meet the quality requirements of downstream customers are called as sale gas. The productivity of LPG and naphtha from the RNGRC is relatively small. They are sold in a push mode. $^{21}$

A utility system including boilers and turbines is used to provide heat and power for the 
RNGRC. We use a set $\operatorname{VUS}_{u}$ to denote the utility system. The gas distillates from separators and deethanizers, and some gas from plug catchers in the RNGRC are used as fuels for boilers in the utility system. Two types of steam including high-pressure steam and low-pressure steam exist in the RNGRC.

\section{Process conditions}

The entire RNGRC involves several operations including condensation, $\mathrm{CO}_{2}$ treating, distillation, compression, and blending operations. With this, the entire planning problem is stated as follows:

Given:

1. Numbers of terminals; minimum and maximum flowrates of raw natural gas from each terminals; compositions, pressures and temperatures of raw natural gas.

2. Numbers of refining processes; minimum and maximum process loads, operating pressures and temperatures; available network of processes.

3. Numbers of customers; product specifications on compositions and pressures, minimum and maximum demands of products.

4. Economic data such as cost of raw natural gas, utility cost, and other fixed cost.

5. Planning horizon.

Determine:

1. Optimal flowrate of raw natural gas for each terminal.

2. Optimal flowrates of products.

3. Optimal operating conditions for refining processes including input and output flowrates, reflux ratios, pressures and temperatures.

4. Optimal operating conditions for the utility system.

Assumptions:

1. All parameters are deterministic.

2. Pressure drop between processes and heat loss from pipes and equipment are ignored. 
3. Hydrocarbons are not dissolved in amine solvents for $\mathrm{CO}_{2}$ capture.

4. Perfect mixing in mixers and pipelines is assumed.

Our objective is to maximize the total profit for the RNGRC in a given period, which is calculated as revenues from final products sale minus operating cost. The operating cost includes the cost of raw natural gas purchase, utility cost, and other fixed cost.

\section{Stream Network Formulation}

The stream network in a RNGRC as shown in Figure 1 is first investigated. The network level focuses on the mass balances, stream directions, operating loads, and pressure and temperature changes of process streams. The detailed chemical composition and energy models of refining processes extracted from fundamentals of thermodynamics and unit operations are not included in the network level. The network model of the RNGRC is formulated as Eqs. 1-25, and includes linear and bilinear constraints.

The RNGRC includes a few of refining processes described in the above section. For example, we can use Figure 2 to present mass and component balances of a plug catcher. In Figure 2, the plug catcher mixes the raw natural gas that comes from pipeline terminals, and separates it into the gas and liquid streams. The gas stream is then split into four branches entering down-stream processes, and the liquid stream enters separators. Hence, we introduce a general network structure to represent the processes in the RNGRC. The general network structure consists of three parts: a mixer, a converter and a splitter, as shown in Figure 3. The symbols in Figure 3 are used to denote total molar flowrate of stream $s$ from process $u$ to $u^{\prime}\left(F_{u, s, u^{\prime}}\right)$, handling capacity of process $u\left(F_{u}\right)$, total molar flowrate of stream $s$ exiting process $u\left(F_{u, s}\right)$, molar fraction of component $c$ in stream $s$ from process $u$ to $u^{\prime}\left(M_{u, s, u^{\prime}, c}\right)$, molar fraction of component $c$ handled by process $u\left(M_{u, c}\right)$, molar fraction of component $c$ in stream $s$ exiting process $u\left(M_{u, s, c}\right)$, pressure of stream $s$ from process $u$ to $u^{\prime}\left(P_{u, s, u^{\prime}}\right)$, operating pressure of process $u\left(P_{u}\right)$, outlet pressure of process $u\left(P_{u}^{o u t}\right)$, and pressure of stream $s$ exiting process $u\left(P_{u, s}\right)$. In Figure 3, the first node is a mixer, in which several streams are 
mixed, and only an outlet stream exits. The second node is a converter, in which the stream from the mixer can be separated into several streams that have different mole fractions and flowrates. For example, the plug catcher separates raw natural gas into a light gas stream and a heavy liquid stream. Meanwhile, pressure and temperature changes can also be done in the converter node, such as the dew point controllers and compressors. The final node is a splitter, in which a stream from a converter is split into several branches that may enter different processes. Splitters can export streams with different flowrates, while without changing their compositions.

\section{Mixers}

The first node in the process is the mixer, in which streams entering the process are mixed together. The mixer is able to receive streams from different sources or processes. Eq. 1 represents the total mass balance of mixing. Eqs. 2 and 3 are used for the mass balance of individual chemical components. Eq. 4 expresses the sum of all mole fractions in a stream. Note that all mole fractions

of a stream should be zero when the corresponding process is not in operation. Hence, we use the binary variable $X_{u, s, u}$, to express the sum of all the mole fractions instead of 1 in Eq. 4 . Eq. 5 is used to identify the existence of stream $s$ from process $u$ to $u$ '.

$$
\begin{gathered}
\sum_{u \notin R N G} \sum_{s:\left(u, s, u u^{\prime}\right) \in S S D} F_{u, s, u^{\prime}}=F_{u^{\prime}} \quad \forall u^{\prime} \in U \\
\sum_{u:\left(u, s, u^{\prime}\right) \in S S D} \sum_{s:\left(u, s, u^{\prime}\right) \in S S D}\left(M_{u, s, u^{\prime}, c} F_{u, s, u^{\prime}}\right)=F_{u^{\prime}, c} \quad \forall u^{\prime} \notin R N G \\
F_{u, c}=F_{u} M_{u, c} \quad \forall u^{\prime} \in U, c \in C \\
\sum_{c \in C} M_{u, s, u^{\prime}, c}=X_{u, s, u^{\prime}} \quad \forall u^{\prime} \notin R N G,\left(u, s, u^{\prime}\right) \in S S D \\
F_{u, s, u^{\prime}} \leq F_{u}^{\max } X_{u, s, u^{\prime}} \quad \forall u^{\prime} \notin R N G,\left(u, s, u^{\prime}\right) \in S S D
\end{gathered}
$$

where binary variables $X_{u, s, u}$, express the operational mass network of RNGRC. Other symbols are explained in the above paragraph.

\section{Converters}

The second node for a process is the converter. The converter divides the feed stream from the mixer into several streams. Eq. 6 represents the operational load limitation of processes. For example, each pipeline terminal has its lower and upper bounds for raw natural gas transportation. 
In order to keep stable operation of raw natural gas wells and fields, the gap between its lower and upper bounds is controlled in practical engineering. Binary variable $X_{u}$ denotes the operation of process $u$, and are used to force the operating load to meet the capacity constraints. Eq. 7 denotes the total mass balance of converter. Eq. 8 represents the mass balance of individual chemical components in the converter. Eq. 9 expresses the sum of all the mole fractions of a stream exiting the converter. Eq. 10 is introduced to express the chemical compositions of raw natural gas from pipeline terminals. Eq. 11 is used to make the chemical compositions of product streams satisfy the requirement of customers. Customers specify the composition and pressure of product streams to meet their own process requirements. When process $u^{\prime}$ is not in operation, binary variables $X_{u}$, equal zero. At the same time, binary variables $X_{u, s, u}$, denoting the streams connecting to process $u$ ' must equal zero. Eq. 12 indicates the logical relationship between these binary variables.

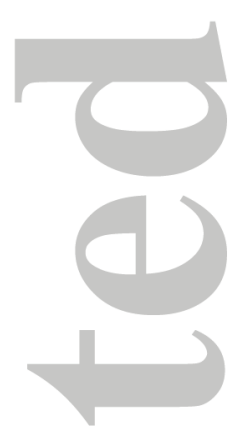

$$
\begin{gathered}
F_{u}^{\min } X_{u} \leq F_{u} \leq F_{u}^{\max } X_{u} \quad \forall u \notin(R N G \cup C U S) \\
F_{u}=\sum_{s:(u, s) \in S F P} F_{u, s} \quad \forall u \notin C U S \\
F_{u, c}=\sum_{s:(u, s) \in S F P}\left(M_{u, s, c} F_{u, s}\right) \quad \forall c \in C, u \notin C U S \\
\sum_{c \in C} M_{u, c}=X_{u} \quad \forall u \in U \\
M_{u, c}=v_{u, c} \quad \forall c \in C, u \in R N G \\
M_{u, c} \leq v_{u, c} \quad \forall u \in C U S,(u, c) \in C S C \\
X_{u, s, u^{\prime}} \leq X_{u^{\prime}} \quad \forall u \notin R N G,\left(u, s, u^{\prime}\right) \in S S D
\end{gathered}
$$

where parameters $F_{u}^{\min }$ and $F_{u}^{\max }$ are the lower and upper bounds of the operational load of process $u$, respectively; $v_{u, c}$ is the mole fraction of component $c$ in the raw natural gas from terminal $u$, or the mole fraction of component $c$ in the product specified by customer $u$.

\section{Splitters}

The splitter is the last node of a process. The splitter divides a stream from the converter into several streams with the same chemical components. Eq. 13 represents the total mass balance of a splitter. Eq. 14 forces the molar flowrates of streams exiting the splitter to be zero when the corresponding process shuts off. Eq. 15 represents the mass balance for individual chemical components in the splitter. Eq. 16 expresses the sum of all the mole fractions of a stream exiting 
processes. Note that Eq. 16 is the same as Eq. 4 when Eq. 15 is held.

$$
\begin{gathered}
F_{u, s}=\sum_{u^{\prime}:\left(u, s, u^{\prime}\right) \in S S D} F_{u, s, u^{\prime}} \quad \forall u \notin C U S,(u, s) \in S F P \\
F_{u, s} \leq F_{u}^{\max } X_{u} \quad \forall u \notin C U S,(u, s) \in S F P \\
M_{u, s, c}=M_{u, s, u^{\prime}, c} \quad \forall c \in C, u \notin C U S,\left(u, s, u^{\prime}\right) \in S S D \\
\sum_{c \in C} M_{u, s, c}=X_{u} \quad \forall u \notin C U S,(u, s) \in S F P
\end{gathered}
$$

\section{Pressure constraints}

Pressure is a key factor that affects energy efficiency and gas quality in a RNGRC. We model the pressure change from pipeline terminals to customers as Eqs. 17-23. First, Eq. 17 is used to express the pressure of raw natural gas at pipeline terminals. Parameter $\rho_{u}$ is the pressure of raw natural gas entering RNGRCs, or the pressure of product specified by customer $u$.

$$
P_{u}^{\text {out }} \leq \rho_{u} \quad \forall u \in R N G
$$

Second, according to fluid dynamics, the operating pressure of a process (denoted as $P_{u}$ ) should not exceed the pressure of each feed stream $\left(P_{u, s, u}\right)$ entering it. The operating pressure of a process has no relationship with a stream if the stream does not enter it. Hence, Eq. 18 is listed to indicate the relationship for pressure.

$$
P_{u^{\prime}} \leq P_{u, s, u^{\prime}}+P_{u, s, u^{\prime}}^{\max }\left(1-P_{u, s, u^{\prime}}\right) \quad \forall u^{\prime} \notin R N G,\left(u, s, u^{\prime}\right) \in S S D
$$

Third, the outlet pressure of a process (denoted as $P_{u}^{\text {out }}$ ) should equal the operating pressure $\left(P_{u}\right)$ plus the pressure change $\left(\Delta P_{u}\right)$ in the process.

$$
P_{u}^{\text {out }}=P_{u}+\Delta P_{u} \quad \forall u \notin C U S
$$

Fourth, the pressure change in a process $u$ is limited by its hardware capacity (denoted as $\left.\Delta P_{u}^{\max }\right)$. A binary parameter $\chi_{u}$ is defined to indicate whether the pressure of a stream $s$ in a process $u$ can change or not. The value of binary parameter $\chi_{u}$ is determined by process design specifications. Hence, Eq. 20 is formulated. The pressure change is further related to product specification and energy requirements in the following process models.

$$
\Delta P_{u} \leq \Delta P_{u}^{\max } \chi_{u} \quad \forall u \notin C U S
$$

Last, the pressures of streams is constrained. The pressure of stream exiting a process is not greater than the outlet pressure of the process, as represented in Eq. 21. Eq. 22 expresses the 
relationship for the pressure of stream exiting a process and entering another process. Eq. 23 enforces product streams to meet the pressure specifications of customers.

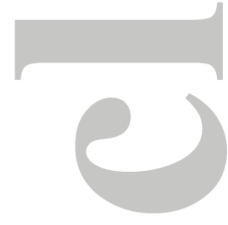

$$
\begin{gathered}
P_{u, s} \leq P_{u}^{\text {out }} \quad \forall u \notin C U S,(u, s) \in S F P \\
P_{u, s, u^{\prime}} \leq P_{u, s} \quad \forall u \notin C U S,\left(u, s, u^{\prime}\right) \in S S D \\
\rho_{u} \leq P_{u} \quad \forall u \in C U S
\end{gathered}
$$

\section{Temperature constraints}

Although temperature is not a key parameter as pressure in a RNGRC, it is used to control the dew point at the dew point controller. The temperature at the dew point controller is related to the quality of sale gas and energy requirement for refrigeration. To model the temperature change in a process $u$, two variables $T_{u}$ and $\Delta T_{u}$ are used to denote the operating temperature and temperature change of a process $u$, respectively. Then, the temperature change of a process $u$ should be the difference between the reference temperature and the final operating temperature. Eq. 24 represents the temperature relationship in the dew point controller.

$$
T_{u}=\tau_{u}^{b a s}-\Delta T_{u} \quad \forall u \in D P C
$$

where parameter $\tau_{u}^{b a s}$ is the reference temperature of a process $u$.

Similar to parameter $\chi_{u}$, binary parameter $\chi_{u}^{\prime}$ is defined to indicate whether a process is able to change the temperature or not. The value of $\chi_{u}^{\prime}$ is specified according to process design. The temperature change in a process should not exceed its maximum temperature change $\left(\Delta T_{u}^{\max }\right)$, as represented in Eq. 25.

$$
\Delta T_{u} \leq \Delta T_{u}^{\max } \chi_{u}^{\prime} \quad \forall u \in D P C
$$

\section{Thermodynamic Model}

As discussed previously, vapor-liquid phase equilibrium is involved in the plug catchers, separators and dew point controllers. We define parameter $K_{u, c}$ to denote the vapor-liquid equilibrium ratio of component $c$, which is a function of temperature, pressure, and composition of the fluid. A large number of curve-fitted expressions were proposed to calculate the value of $K_{u, c}$, 
among which the correlation method presented by Wilson ${ }^{22}$ is the best suitable for natural gas and light hydrocarbons. The correlation proposed by Wilson ${ }^{22}$ is given in Eq. 26.

$$
K_{u, c}=\frac{P_{c}^{*}}{P_{u}} e^{5.37\left(1+\omega_{c}\right)\left(1-\frac{T_{c}^{*}}{T_{u}}\right)} \quad \forall u \in(P C T \cup D P C \cup S E P)
$$

where parameters $P_{c}^{*}, T_{c}^{*}$ and $\omega_{c}$ are the critical pressure, critical temperature, and acentric factor of component $c$, respectively. $P_{u}$ and $T_{u}$ are the operating pressure and temperature of a process $u$, respectively. According to Eq. 26, the lower and upper bounds of $K_{u, c}$ can be determined by physical properties of components and temperature and pressure bounds of process operation. This expedites the convergence in the solution procedure of the MINLP model.

From Eq. 26, it can be concluded that the vapor-liquid equilibrium ratio $K_{u, c}$ never equals zero regardless of whether a process $u$ is in operation. As concluded from above, if a process is not in operation (i.e., $X_{u}=0$ ), the vapor-liquid equilibrium ratio should also be zero. To solve this situation, we define an alternative vapor-liquid equilibrium ratio denoted as $K_{u, c}^{\wedge}$. The relationship between $K_{u, c}^{\wedge}$ and $K_{u, c}$ can be given in Eqs. 27-29.

$$
\begin{gathered}
K_{u, c}^{\wedge} \leq v X_{u} \quad \forall c \in C, u \in(P C T \cup D P C \cup S E P) \\
K_{u, c}^{\wedge} \leq K_{u, c} \quad \forall c \in C, u \in(P C T \cup D P C \cup S E P) \\
K_{u, c}-v\left(1-X_{u}\right) \leq K_{u, c}^{\wedge} \quad \forall c \in C, u \in(P C T \cup D P C \cup S E P)
\end{gathered}
$$

where parameter $v$ is of a large value. Note that $K_{u, c}^{\wedge}=K_{u, c}$ when $X_{u}=1$.

\section{Process Models}

Several energy-intensive processes such as dew point controllers and compressors exist in a RNGRC, which are the main sources of energy consumptions in the entire RNGRC. Although simple mathematical expressions like linear correlations can be employed to represent the energy requirements of these energy-intensive processes, their inaccuracy often leads to incorrect estimation of the operation cost related to energy consumption. ${ }^{10}$ In the following, rigorous models are proposed based on thermodynamics and unit operation principles to represent the mass balance and energy requirements for these energy-intensive processes. 


\section{Plug catcher and separator}

Plug catchers and separators are usually used to separate raw natural gas into gas and liquid phases. They can be treated as gas-liquid separators in which the vapor-liquid equilibrium ratio $\left(K_{u, c}^{\wedge}\right)$ governs the flowrates and compositions of streams. The relationship of the mole fractions of component $c$ in gas $\left(M_{u, s, c}\right)$ and liquid $\left(M_{u, s^{\prime}, c}\right)$ phases can be expressed using Eq. 30.

$$
M_{u, s, c}=K_{u, c}^{\wedge} M_{u, s^{\prime}, c} \quad \forall c \in C, s \in L S, s^{\prime} \in H S, u \in(P C T \cup D P C \cup S E P),(u, s) \in S F P,\left(u, s^{\prime}\right) \in \operatorname{SFP}
$$

\section{Dew point controller}

Dew point controllers are designed to condense some heavy components from gas streams in order to meet gas product specifications. The vapor-liquid equilibrium in dew point controllers can be expressed by Eqs. 26-30. The energy requirement for the dew point controllers is expressed as Eqs. 31 and 32. Eq. 31 is used to calculate the energy requirement, resulting from the temperature change $\Delta T_{u}$ in the dew point controller. The energy requirement includes two parts: the sensible heat for temperature descending and the latent heat for the condensation of heavy hydrocarbons. The cold utility is produced by a propane refrigeration system with energy efficiency $\eta_{u}$. Hence, power consumption is expressed as Eq. 32. Parameters $\varepsilon_{c}$ and $\epsilon_{c}$ are the specific heat capacity and latent heat of chemical component $c$, respectively.

$$
\begin{gathered}
\Delta T_{u} \sum_{c \in C}\left(\varepsilon_{c} F_{u, c}\right)+\sum_{s:(u, s) \in S F P, s \in H S}\left(F_{u, s} \sum_{c \in C}\left(\epsilon_{c} M_{u, s, c}\right)\right)=Q_{u} \quad \forall u \in D P C \\
E_{u}=\eta_{u} Q_{u} / 3600 \quad \forall u \in D P C
\end{gathered}
$$

As a result, Eqs. 26-32 can be used to obtain the mass balance and energy requirement for the dew point controller.

\section{$\mathrm{CO}_{2}$ treating process}

$\mathrm{CO}_{2}$ treating process is designed to remove $\mathrm{CO}_{2}$ from raw natural gas. Amine solvents are often used as medium streams to capture $\mathrm{CO}_{2}$ from raw natural gas in an absorber column. The $\mathrm{CO}_{2}$-rich amine solvents are regenerated in a stripper column. The entire $\mathrm{CO}_{2}$ treating process is shown in

Figure 4. To avoid repeated letdown and compression of natural gas and intensify $\mathrm{CO}_{2}$ absorption, the absorber column is operated at a relatively high pressure often over $2.2 \mathrm{MPa}$, whereas the 
stripper column is operated at a low pressure to make $\mathrm{CO}_{2}$ release easier and reduce utility requirement. Hasan et al. ${ }^{23}$ investigated process optimization and energy integration for $\mathrm{CO}_{2}$ capture. We assume that the amine solvents only absorb $\mathrm{CO}_{2}$, which is very close to engineering practice and hence is widely used. ${ }^{24}$ As a result, Eq. 8 for mass balance is further formulated as Eq. 33 for the gas stream entering absorbers and the purified gas stream exiting absorbers. Meanwhile, Eq. 34 is used for the stream $\mathrm{CO}_{2}$ exiting regenerators.

$$
\begin{aligned}
& F_{u, c}=\sum_{s:(u, s) \in S F P, s \in L S}\left(M_{u, s, c} F_{u, s}\right) \quad \forall c \neq c o_{2}, u \in D C P \\
& M_{u, s, c}=X_{u} \quad \forall c=C O_{2}, s \in H S, u \in D C P,(u, s) \in S F P
\end{aligned}
$$

The $\mathrm{CO}_{2}$ treating process is highly energy intensive. The energy required in the $\mathrm{CO}_{2}$ treating process has two parts. One is pressure improvement of lean solvent from regenerators to absorbers, and the other is energy required by the reboilers of regenerators. Because of the large molar flowrate and pressure improvement of lean solvent in the $\mathrm{CO}_{2}$ treating process, the pump consumes a lot of power. The molar flowrate of solvent is related to the quantity of $\mathrm{CO}_{2}$ removal and the ability of its absorption. The molar flowrate of solvent $\left(F_{u}^{s o l}\right)$ is expressed as Eq. 35. Parameter $\kappa_{u}$ is regressed from industrial operating data, indicating the ability of solvent absorbing $\mathrm{CO}_{2}$. Mofarahi et al. ${ }^{25}$ proposed the interrelationship of solvent molar flowrate and $\mathrm{CO}_{2}$ removal. Parameter $\Delta \rho_{u}$ is the pressure drop between absorbers and regenerators, $\eta_{u}$ is pump efficiency in the $\mathrm{CO}_{2}$ treating processes, and $\gamma^{\text {sol }}$ is the molar density of solvent. As a result, the power consumed $\left(E_{u}\right)$ by pump is calculated using Eq. 36 .

$$
\begin{gathered}
F_{u}^{s o l}=\kappa_{u} F_{u, s} \quad \forall s \in H S, u \in D C P,(u, s) \in S F P \\
E_{u}=\frac{\Delta \rho_{u} F_{u}^{s o l}}{3600 \gamma^{s o l} \eta_{u}} \quad \forall u \in D C P
\end{gathered}
$$

The required energy for the reboiler in the regenerator is often supplied by low-pressure steam from utility systems. The heat balance in the regenerator suggests that the heat provided to the reboiler should equal the heat removed from the condenser, the reaction heat for $\mathrm{CO}_{2}$ desorption, and the heat to increase the solvent temperature from the inlet to outlet of regenerator. The three items on the right hand of Eq. 37 denote the three parts of heat. The rich solvent entering the 
regenerator is the $\mathrm{CO}_{2}$-saturated solution, and the lean solvent exiting the stripper has a lower $\mathrm{CO}_{2}$ content. The distillate stream from the regenerator should equal the absorbed $\mathrm{CO}_{2}$ and a trace of solvent. We use the molar flowrate of absorbed $\mathrm{CO}_{2}$ instead of the total molar flowrate of distillate stream from the regenerator, and the trace of solvent in distillate is ignored. Hence, the heat removed from the condenser is expressed as the first item on the right hand of Eq. 37.

$$
Q_{u}=\epsilon^{r e g} \iota^{r e g} \sum_{s:(u, s) \in S F P, s \in S L} F_{u, s}+\delta^{r e g} \sum_{s:(u, s) \in S F P, s \in S L} F_{u, s}+\varepsilon^{s o l} \Delta \tau^{r e g} F_{u}^{s o l} \quad \forall u \in D C P
$$

where parameters $\epsilon^{r e g}, \iota^{r e g}, \delta^{r e g}, \varepsilon^{\text {sol }}$ and $\Delta \tau^{r e g}$ are the specific latent heat of reflux stream in the regenerator, the reflux ratio of regenerator, the specific reaction heat of $\mathrm{CO}_{2}$ desorption, the specific heat capacity of solvent, and the temperature difference between solvent entering and exiting the regenerator, respectively.

\section{Dehydration}

Dehydration is used to remove trace amount of water in gas streams out from $\mathrm{CO}_{2}$ treating processes. Solvent, molecular sieve and silicone are often used to remove trace amount of water. Silicone is widely used due to its lower energy cost than others. ${ }^{25}$ Silicone has to be re-installed after a certain period. The operating cost for dehydration process is mainly from the cost of silicone, which is specified and included in the fixed cost.

\section{Compression process}

Natural gas has to be compressed to satisfy pressure specifications of downstream customers. Gas compression is designed to bring gas from a certain pressure to a higher pressure by means of mechanical work. The molar flowrates and chemical components of streams are the same at the inlets and outlets of compressors since there is no phase change during compression. The compression ratio denoted as $R_{u}$ is calculated in Eq. 38 .

$$
R_{u} P_{u}=P_{u}^{\text {out }} \quad \forall u \in C O M
$$

where $P_{u}$ is the inlet pressure of a compressor, and $P_{u}^{\text {out }}$ is the outlet pressure of a compressor.

Two ideal compression, isothermal and isentropic compression, are often used to model a

practical compression process. ${ }^{11,12}$ For isentropic compression, isentropic efficiency is defined to 
calculate the practical enthalpy change. Hence, the required power (denoted as $E_{u}$ ) is computed using Eq. 39.

$$
E_{u}=\frac{1}{\eta_{u}} \sum_{c \in C}\left(\varepsilon_{c} F_{u, c}\right)\left[\left(R_{u}\right)^{\frac{\theta_{u}-1}{\theta_{u}}}-1\right] \quad \forall u \in C O M
$$

The isentropic exponent $\theta_{h}$ is defined as the ratio of heat capacities of gas streams at constant pressure and temperature. The heat capacities of real gases are a function of the pressure and temperature. For light hydrocarbon gas, the isentropic exponent $\theta_{u}$ can be accurately obtained using Eq. 40, in which parameter $\varphi_{u}$ was given by Moshfeghian. ${ }^{26}$

$$
\theta_{u}=1.3-0.31\left(\varphi_{u}-0.55\right) \quad \forall u \in C O M
$$

\section{Deethanizer and stabilizer}

Two distillation columns (i.e., a deethanizer and a stabilizer) are used to separate LPG and naphtha from raw natural gas. The content of $\mathrm{C}^{2-}$ in the bottom stream of the deethanizer must be controlled to guarantee the quality of LPG. Principally, the content of $\mathrm{C}^{3+}$ in the distillate of the deethanizer should also be controlled to avoid LPG loss. However, more $\mathrm{C}^{3+}$ in the distillate leads to high heating values since the distillate is finally used as a fuel in the utility system. Therefore, the optimal content of $\mathrm{C}^{3+}$ in the distillate is determined from the optimization. The distillate and bottom streams from the stabilizer have to be specified in order to meet the specifications of LPG and naphtha products.

Eqs. 41 and 42 express the purification of distillate and bottom streams from the deethanizer and stabilizer. Parameters $v_{u}^{d i s}$ and $v_{u}^{\text {bot }}$ are the composition specifications on the distillate and bottom streams, respectively.

$$
\begin{gathered}
\sum_{s:(u, s) \in S F P, S \in S L} \sum_{c \in H C D} M_{u, s, c} \leq v_{u}^{d i s} X_{u} \quad \forall u \in S T A \\
\sum_{s:(u, s) \in S F P, s \in S H} \sum_{c \in L C D} M_{u, s, c} \leq v_{u}^{b o t} X_{u} \quad \forall u \in(D E E \cup S T A)
\end{gathered}
$$

For the distillation with multiple components, the minimum reflux ratio $N_{u}$ is expressed in Eq. 43, which is related to separation purification $\left(M_{u, s, c}\right)$, relative volatility $\left(\alpha_{u, c}\right)$ and a column parameter $\left(\beta_{u}\right) .{ }^{27} \mathrm{C}_{2} \mathrm{H}_{6}$ and $\mathrm{C}_{4} \mathrm{H}_{10}$ are assumed to be the light key components in the deethanizer and stabilizer for the calculation of the relative volatility $\alpha_{u, c}$. 


$$
N_{u}+1=\sum_{s:(u, s) \in S F P, s \in S L} \sum_{c \in C} \frac{\alpha_{u, c} M_{u, s, c}}{\alpha_{u, c}-\beta_{u}} \quad \forall u \in(D E E \cup S T A)
$$

We notice that when the deethanizer or stabilizer is not operated, its minimum reflux ratio should be zero, which is not satisfied for Eq. 43. The following Eq. 44 is then proposed to replace Eq. 43.

$$
N_{u}+X_{u}=\sum_{s:(u, s) \in S F P, s \in S L} \sum_{c \in C} \frac{\alpha_{u, c} M_{u, s, c}}{\alpha_{u, c}-\beta_{u}} \quad \forall u \in(D E E \cup S T A)
$$

where binary variable $X_{u}$ denotes the operation of process $u$.

The heat duty of reboilers in the deethanizer and stabilizer is computed using Eq. 45.

$$
Q_{u}^{r e b}=\sigma_{u} \epsilon_{u}^{r e u} U_{u} \sum_{s:(u, s) \in S F P, S \in S L} F_{u, s}+\psi_{u} X_{u} \quad \forall u \in(D E E \cup S T A)
$$

where parameter $\sigma_{u}$ is defined as the ratio of practical reflux ratio to the minimum reflux ratio, $\epsilon_{u}^{r e u}$ is the specific latent heat of the reflux stream in the deethanizer or stabilizer, and $\psi_{u}$ is generated from the correlated operating data.

The required cold utility for condensers at the top of the deethanizer and stabilizer is ignored since it is inexpensive compared to hot utility in the RNGRC.

\section{Pipeline blending}

Different grades of natural gas from different processes such as plug catchers, dew point controllers, dehydration and compressors are mixed together in pipelines to meet sale gas specifications for downstream customers, as shown in Figure 1. The pressure of pipeline must not be larger than the smallest pressure of feed streams, and not less than the pressure specifications of customers. The formulation on the network level suffices to express the constraints of mass and pressure for pipeline blending.

\section{Utility System Model}

A utility system, including boilers and steam turbines (See Figure 5), is configured to supply heat and power to the RNGRC. Un-purified gas from separators and deethanizers is used as fuel in boilers. Some gas from plug catchers is replenished if un-purified gas is not enough. Boilers 
produce high-pressure steam that is directly fed into back pressure turbines for power generation. Low-pressure steam released from back pressure turbines is first used as heat sources at reboilers in some processes such as regenerators, deethanizers, and stabilizers. The excess low-pressure steam can enter condensing turbines for power generation. The power generated from back pressure and condensing turbines is provided for dew point controllers, solvent pumps, gas compressors and other power sinks in the RNGRC. The power purchased from the grid is employed to balance the power requirement in the entire RNGRC.

\section{Boilers}

We have investigated the model of the utility system in our previous publication. ${ }^{28}$ The boiler model from Shang and Kokossis ${ }^{29}$ is modified to express the correlations between the flowrate of generated steam and required fuel amount, as shown in Eq. 46. In the boiler hardware model, the heat requirement of steam production is divided into three parts: the boiler feed-water preheating, water vaporization and steam superheating. Binary variable $X_{b}$ is used to denote whether boiler $b$ is in operation. Continuous variables $G_{b}, Q_{b}$ and $F_{b}$ denote the flowrate of steam produced, the heat absorbed, and the fuel consumed by boiler $b$, respectively. Eqs. 47 and 48 are used for the heat and mass balances for fuel. The total heat of boiler is related to the composition of fuel, which changes with the operation of separators and deethanizers. Boiler $b$ must satisfy its minimum $\left(G_{b}^{\min }\right)$ and maximum $\left(G_{b}^{\max }\right)$ operational load, as represented in Eq. 49.

$$
\begin{gathered}
{\left[\sigma_{b} G_{b}^{\max } X_{b}+\left(1+\beta_{b}\right) G_{b}\right]\left[\left(1+\lambda_{b}\right) \varepsilon^{w a t}\left(\tau^{\text {shs }}-\tau^{\text {wat }}\right)+\epsilon^{\text {shs }}+\varepsilon^{s t e}\left(\tau^{\text {ohs }}-\tau^{s h s}\right)\right]=Q_{b} \quad \forall b \in B} \\
Q_{b}=F_{b} \sum_{u \in V U S} \sum_{c \in C}\left(\epsilon_{c} C_{u, c}\right) \quad \forall b \in B \\
\sum_{b \in B} F_{b}=\sum_{u \in V U S} F_{u} \\
G_{b}^{\text {min }} X_{b} \leq G_{b} \leq G_{b}^{\max } X_{b} \quad \forall b \in B
\end{gathered}
$$

where parameters $\sigma_{b}$ and $\beta_{b}$ are derived from design or operating data; parameters $G_{b}^{\min }, G_{b}^{\max }$ and $\lambda_{b}$ are the lower and upper bounds, and the ratio of blowdown of boiler $b$, respectively; parameters $\tau^{\text {wat }}, \tau^{\text {shs }}$ and $\tau^{\text {ohs }}$ are the temperatures of boiler feed water, saturated water and overheated high-pressure steam, respectively; parameters $\epsilon^{\text {shs }}, \varepsilon^{\text {ste }}$ and $\varepsilon^{\text {wat }}$ are the specific latent 
heat of water, the specific heat capacity of high-pressure steam, and the specific heat capacity of water, respectively.

\section{Turbines}

Steam turbines are used for power generation in a RNGRC. Although several types of turbines exist such as back pressure and condensing turbines, the models of these steam turbines are often grouped together instead of using complex turbines for complex turbines simulation in the general practice. ${ }^{29}$ The model for a simple steam turbine ${ }^{30}$ is introduced to explore the relationship between the output power and input steam flowrate, as shown in Eq. 50.

$$
3600 E_{d}=\frac{6}{5} \frac{1}{\beta_{d}}\left(\epsilon_{d}^{i s e}-\frac{\sigma_{u}}{G_{d}^{\text {max }}}\right)\left(G_{d}-\frac{1}{6} G_{d}^{\max } X_{d}\right) \quad \forall d \in D
$$

where binary variable $X_{d}$ is used to denote whether turbine $d$ is in operation. Continuous variables $E_{d}$ and $G_{d}$ denote the power generated and the flowrate of steam consumed by turbine $d$, respectively. Parameter $\epsilon_{d}^{i s e}$ is the specific isentropic enthalpy change of stream in turbine $d$. Parameters $\beta_{d}$ and $\sigma_{d}$ are regression parameters, which can be founded in the literature. ${ }^{30}$

As indicated in Eq. 50, the isentropic efficiencies of turbines vary with the flow rate of the steam entering turbines, resulting in a slight temperature change of the steam exiting turbines. We assume that the slight temperature change of the steam exiting the back pressure turbines has no impact on the steam network. As a result, the temperatures of the steam networks are assumed to be constant.

The operational load of turbine $d$ must meet its minimum $\left(E_{d}^{\min }\right)$ and maximum $\left(E_{d}^{\max }\right)$ load, as expressed in Eq. 51 .

$$
E_{d}^{\min } X_{d} \leq E_{d} \leq E_{d}^{\max } X_{d} \quad \forall d \in D
$$

\section{Steam and heat balance}

Generally, two types of steam including high-pressure and low-pressure steam are generated in a RNGRC. The high-pressure steam is generated from boilers, and consumed by back pressure turbines or supplied to nearby plants. We define $G_{b}$ as the total molar flowrate of high-pressure steam generated from boiler $b$ and $G_{d}$ as the molar flowrate of high-pressure steam entering back 
pressure turbine $u$. The total amount of high-pressure steam entering back pressure turbines plus the steam export should not exceed the total amount generated from boilers, which is represented in Eq.

52. Parameter $\mu$ is the flowrate of steam export.

$$
\sum_{d \in B P T} G_{d}+\mu \leq \sum_{b \in B} G_{b}
$$

The sources of low-pressure steam is back pressure turbines, and the sink is the reboilers of processes and condensing turbines. The total amount of low-pressure steam used in the reboilers of processes and condensing turbines should not exceed the total amount generated from back pressure turbines, as represented in Eq. 53. The first item on the left right side of Eq. 53 is the molar flowrate of low-pressure steam used in the regenerators, deethanizers and stabilizers. We assume that the latent heat of low-pressure steam is used as hot utility in order to keep in line with engineering practice. The second item is the total amount of steam entering condensing turbines.

$$
\frac{\sum_{u \in(D C P \cup D E E \cup S A T)} Q_{u}}{\epsilon^{l p s}}+\sum_{d^{\prime} \in C D T} G_{d^{\prime}} \leq \sum_{d \in B P T} G_{d}
$$

where $Q_{u}$ is the heat duty of a reboiler in process $u ; \epsilon^{l p s}$ is the specific latent heat of low-pressure steam.

Power is generated by turbines or taken from the grid. Meanwhile, power can be uploaded if turbines can produce more. The generated power is mainly used for refrigeration, compression, and lean solvent transportation in a RNGRC. The power used for other processes in the RNGRC is quite small and hence is assumed as a constant (denoted as $\xi$ ). We define $E_{u}$ as the power required by process $u, E_{d}$ as the power generated from turbine $d$ and $P B$ is the power purchased from the grid. The power balance in the RNGRC is represented in Eq. 54.

$$
\xi+\sum_{u \in(D P C \cup D C P \cup C O M)} E_{u} \leq P B+\sum_{d \in D} E_{d}
$$

\section{Operational MINLP Model}

\section{Economic objective}

The objective is to obtain maximum profit for a given planning period. The total profit $(O B J)$ is calculated as the revenue from final product sale (denoted as $P S$ ) minus the purchase cost of raw 
natural gas (denoted as $R C$ ), utility cost (denoted as $U C$ ), and other fixed costs (denoted as $\pi$ ) as indicated in Eq. 55.

$$
O B J=P S-(R C+U C+\pi)
$$

The final products include sale gas, LPG and naphtha. The revenue from the sale of these products is computed in Eq. 56. The costs of raw natural gas and power purchase are expressed in Eq. 57 and 58, respectively. Power can be produced from the RNGRC. It can be uploaded or downloaded from the grid after it balances in the entire RNGRC. $P B$ in Eq. 58 is defined as a real variable that represents power balance. It is expressed in the utility system model. Parameter $\zeta$ is the price of raw natural gas, products or power.

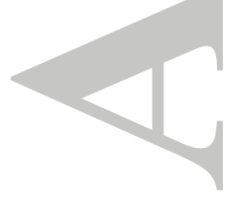

$$
\begin{gathered}
P S=\sum_{u \in C U S}\left(\zeta_{u} F_{u}\right) \\
R C=\sum_{u \in R N G}\left(\zeta_{u} F_{u}\right) \\
U C=\zeta^{\text {pow }} P B
\end{gathered}
$$

\section{Lower and upper bounds}

Tight variable bounds play a significant role in improving the efficiency of the proposed MINLP model. We notice that the flowrates of inlet and outlet streams should not exceed their process capacity, as expressed in Eqs. 6, 49 and 51. The purchase amount of natural gas and the sale amount of products should lie in their minimum and maximum supply or demand amount as shown in the Eq. 59.

$$
F_{u}^{\min } \leq F_{u} \leq F_{u}^{\max } \quad \forall u \in(R N G \cup C U S)
$$

The purchase cost of raw natural gas (RC) and the revenue from products sale (PS) can be bounded using Eqs. 60 and 61, respectively.

$$
\begin{aligned}
& \sum_{u \in C U S}\left(\zeta_{u} F_{u}^{\text {min }}\right) \leq P S \leq \sum_{u \in C U S}\left(\zeta_{u} F_{u}^{\text {max }}\right) \\
& \sum_{u \in R N G}\left(\zeta_{u} F_{u}^{\text {min }}\right) \leq R C \leq \sum_{u \in R N G}\left(\zeta_{u} F_{u}^{\text {max }}\right)
\end{aligned}
$$

The operating pressures and temperatures of processes are bounded using Eqs. 62 and 63, respectively.

$$
\begin{array}{ll}
P_{u}^{\min } \leq P_{u} \leq P_{u}^{\max } & \forall u \notin(R N G \cup C U S) \\
T_{u}^{\text {min }} \leq T_{u} \leq T_{u}^{\text {max }} & \forall u \notin(R N G \cup C U S)
\end{array}
$$


The vapor-liquid equilibrium ratio $K_{u, c}$ can be bounded through Eqs. 64 .

$$
\frac{P_{c}^{*}}{P_{u}^{\max }} e^{5.37\left(1+\omega_{c}\right)\left(1-\frac{T_{c}^{*}}{\left.T_{u}^{\min }\right)}\right.} \leq K_{u, c} \leq \frac{P_{c}^{*}}{P_{u}^{\min }} e^{5.37\left(1+\omega_{c}\right)\left(1-\frac{T_{c}^{*}}{\left.T_{u}^{\max }\right)}\right.} \quad \forall u \in(P C T \cup D P C \cup S E P)
$$

\section{Model and reformation}

The operational planning model for the RNGRC is defined as MP presented below.

(MP) max $O B J$ (total profit)

s.t. $\quad$ Eqs. 1-25 (network constraints);

Eqs. 26-29 (thermodynamic constraints);

Eqs. 30-39, 41, 42, 44, 45 (process constraints);

Eqs. 46-54 (utility constraints);

Eqs. 55-58 (objective constraints)

Eqs. 59-64 (lower and upper bounds)

The model MP involves bilinear, exponential, and sigmoidal items (see Table 1), which makes the model MP nonconvex. The planning decisions on whether a process is in operation make the entire model MP a large-scale nonconvex MINLP optimization model, which is extremely challenging.

The model is very challenging to solve it directly. The nonlinear constraint Eq. 26 used to calculate the vapor-liquid phase equilibrium ratios for chemical components in different operating temperatures and pressures is complex and nonconvex as verified by eigenvalue calculation. Hence, we attempt to reformulate it. Applying the logarithmic operator on both sides of Eq. 26, four constraints in Eq. 26A are obtained. As a result, the nonlinear constraint Eq. 26 can be replaced by linear, bilinear and exponential terms. We note that the phase equilibrium ratio $K_{p, c}$ and pressure $P_{p}$ in the model are positive for RNGRCs. Hence, the logarithmic operator can be used for Eq. 26.

$$
\left.\begin{array}{c}
K_{u, c}+P_{u}-V Y T_{u}=\ln \left(P_{c}^{*}\right)+5.37\left(1+\omega_{c}\right)+Z_{u, c} \\
K_{u, c}=e^{K_{u, c}^{\prime}} \\
P_{u}=e^{P_{u}^{\prime}} \\
Z_{u, c} T_{u}=5.37\left(1+\omega_{c}\right) T_{c}^{*}
\end{array}\right\} \quad \forall c \in C, u \in(P C T \cup D P C \cup S E P)
$$


Eq. 39 includes the item of decision variables multiplying power. We can use intermediate variables $Z_{u}$ to replace the power term, and then reformulate it into two Eqs. 39A and 39B.

$$
\begin{gathered}
Z_{u}=\left(R_{u}\right)^{\frac{\theta_{u-1}}{\theta_{u}}} \quad \forall u \in C O M \\
E_{u}=\frac{1}{\eta_{u}} \sum_{c \in C}\left(\varepsilon_{c} F_{u, c}\right)\left[Z_{u}-1\right] \quad \forall u \in C O M
\end{gathered}
$$

As a result, the nonconvex constraints in the MINLP model include two nonconvex types: bilinear and power. These nonconvex terms can be converted into their respective convex envelopes and addressed by existing solvers. Readers are referred to the books ${ }^{31,32}$ for a comprehensive treatment.

We redefine the operational optimization problem of RNGRC as RP presented below.

(RP) max $O B J$ (total profit)

s.t. Eqs. 1-25 (network constraints);

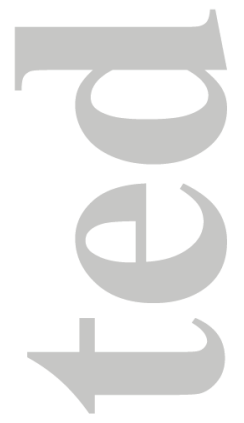

Eqs. 26A, 27-29 (thermodynamic constraints);

Eqs. 30-38, 39A, 39B, 41, 42, 44, 45 (process constraints);

Eqs. 46-54 (utility constraints);

Eqs. 55-58 (objective constraints)

Eqs. 59-64 (lower and upper bounds)

Problem RP is equivalent to MP. According to the properties of constraints, there are bilinear, power and exponential constraints in the RP model. Global optimization for MINLP models including these terms were widely investigated, and corresponding commercial solvers were developed. ${ }^{33}$ In this study, three global optimization solvers ANTIGONE V1.1 ${ }^{34}$, BARON $15.9^{35}$ and LINDOGLOBAL $9.0^{36}$ in the modeling system GAMS 24.5.3 are employed to solve the RP model for an industrial example, and solution performance is also discussed in the example.

\section{Computational Results}

A real industrial RNGRC from South China is taken as an example in this study. Raw natural 
gas from two subsea pipeline terminals are fed into the RNGRC and refined into different grades of gas, which are mixed together in pipelines to meet the specifications of three downstream customers. The complete data are given in Table 2. We use n-alkane to represent chemical components in the raw natural gas. Complete data of chemical components can also be used for the RNGRC if detailed monitoring data are available. All streams and processes in the RNGRC are listed in Tables A1-A2. The amine solvent for $\mathrm{CO}_{2}$ capture in the RNGRC is Methyl diethanolamine (MDEA). A utility system for the RNGRC is illustrated in Figure 5. The temperature and pressure of high-pressure steam are $425{ }^{\circ} \mathrm{C}$ and $4.52 \mathrm{MPa}$, respectively. The temperature and pressure of low-pressure steam are $197^{\circ} \mathrm{C}$ and $0.6 \mathrm{MPa}$, respectively. The power price is about $\$ 162 / \mathrm{MW} \cdot \mathrm{h}$. All parameters in the proposed model are updated using the operating data from the RNGRC. The fixed cost, which depends on the specific RNGRC, is assumed to be zero.

The example is solved using three deterministic global optimization solvers (ANTIGONE V1.1 $1^{34}$, BARON $15.9^{35}$ and LINDOGLOBAL 9.0 36 ) in the modeling system GAMS 24.5 .3 on an Intel(R) Core(TM) i5-4670 3.40 GHz PC running Windows 8 system. The maximum CPU time is set as 100 hours. The computational results are presented in Table 3. The model involves 136 binary variables, 2,461 continuous variables, 2,457 linear constraints, 574 bilinear constraints, 81 power exponential constraints, and 9 power constraints. Best feasible solutions are obtained from ANTIGONE $^{34}$ and LINDOGLOBAL ${ }^{36}$, while no feasible solution is found using BARON ${ }^{35}$ in 100 hours. The execution time of ANTIGONE ${ }^{34}$ is the shortest among the three solvers. The execution time of LINDOGLOBAL ${ }^{36}$ is also acceptable for solving large-scale real industrial problems. The objective function values obtained from ANTIGONE $^{34}$ and LINDOGLOBAL ${ }^{36}$ are 291,040 and 286,433 , respectively. LINDOGLOBAL ${ }^{36}$ gives an upper bound of 289,300 , which is lower than the lower bound of 291,040 obtained from ANTIGONE. ${ }^{34}$ This is because LINDOGLOBAL ${ }^{36}$ may incorrectly cut the optimum region during the solution procedure.

The best profit for the RNGRC from ANTIGONE ${ }^{34}$ reaches $\$ 291,040$ per hour in which the revenue from product sale is $\$ 715,220$ per hour, the raw natural gas cost is $\$ 408,000$ per hour, and 
the power cost is $\$ 16,179$ per hour. The best operational conditions for the RNGRC are given in Tables A3-A6. The flowrate and direction of each chemical component from raw natural gas to products are shown in Figure 6. In order to show the major connections between the crude feeds and products, we ignore the flow streams whose mole fractions are less than $1 \%$ in Figure 6. The widths of lines in Figure 6 are proportionate to the mole flowrates of chemical components.

The present profit from the real operation is $\$ 264,064$ per hour consisting of the revenue of $\$ 648,246$ per hour, the raw natural gas cost of $\$ 381,930$ per hour, and the power cost of $\$ 2,252$ per hour. The present operational conditions for the RNGRC from the real plant are listed in Table A7. Compared to the present operation, the optimal results achieve a significant profit increase of $10.21 \%$. This is mainly due to (a) the throughput and match differences of the two types of raw natural gas; (b) the different distribution of products; (c) the different operation of utility system and power balance. We analyze the three aspects in the sequel.

The present and optimal operations have different throughputs on raw natural gas $2 \#$. For the present operation, the total throughput of raw natural gas is $127,100 \mathrm{kmol} / \mathrm{h}$. Raw natural gas $1 \#$ is $75,000 \mathrm{kmol} / \mathrm{h}$, and raw natural gas $2 \#$ is $52,100 \mathrm{kmol} / \mathrm{h}$. For the optimal results, the total throughput of raw natural gas is $135,000 \mathrm{kmol} / \mathrm{h}$. Raw natural gas $1 \#$ is $75,000 \mathrm{kmol} / \mathrm{h}$, and raw natural gas $2 \#$ is $60,000 \mathrm{kmol} / \mathrm{h}$. Raw natural gas $1 \#$ reaches the maximum supply amount in the present and optimal operations, while raw natural gas $2 \#$ is less in the present operation. The $\mathrm{CO}_{2}$ content in raw natural gas $2 \#$ is much higher than that in raw natural gas $1 \#$, and its price is lower. Nevertheless, the present operation favors to use raw natural gas $1 \#$.

The distribution of sale gas is significantly different for the present and optimal operations. The present operation supplies 55,000, 14,482 and 23,852 kmol/h sale gas for the customer $1 \#, 2 \#$ and $3 \#$, respectively. The optimal operation supplies $30,000,21,663$ and $50,000 \mathrm{kmol} / \mathrm{h}$ sale gas for the customer $1 \#, 2 \#$ and $3 \#$, respectively. Comparing the present and optimal operations, the present operation favors to produce more sale gas for the customer $1 \#$ that reaches the maximum demand amount of $55,000 \mathrm{kmol} / \mathrm{h}$. The specification of customer $1 \#$ is looser on the pressure and 
composition of sale, as shown in Table 2. Hence, the production of sale gas for customer 1 \# can reduce utility consumption. However, the price of sale gas for customer $1 \#$ is the lowest among the three customers.

The present and optimal operations exhibit differences in LPG production. The present operation produces $9,620 \mathrm{kmol} / \mathrm{h}$ LPG. The optimal operation produces $8,362 \mathrm{kmol} / \mathrm{h}$ LPG. The recovery of LPG components is $80.94 \%$ and $65.14 \%$ for the present and optimal operations, respectively. LPG has the highest price among products. LPG is lighter than naphtha, and heavier than sale gas, and is composed of the middle components in raw natural gas. Hence, LPG is very difficult to separate from sale gas, and its production consumes large amounts of energy. A higher recovery ratio of LPG components results in more natural gas consumed as fuels, and reduces the flowrate of sale gas.

The present and optimal operations have significant differences in the utility system and power balance. In the present operation, the fuel gas is consumed at a rate of $7,909 \mathrm{kmol} / \mathrm{h}$, and the cost of power purchase is $\$ 2,252$ per hour. In the optimal operation, the fuel gas is consumed at a rate of $5,921 \mathrm{kmol} / \mathrm{h}$, and the cost of power purchase is $\$ 16,179$ per hour. Hence, the present operation favors the consumption of more natural gas as fuel to reduce the cost of power purchase, and this decreases the flowrates of products.

According to the above analysis, the profitability of the present operation can be improved through changing the throughput of raw natural gas $2 \#$, increasing the sale gas for customer $3 \#$, reasonably reducing the production of LPG, and purchasing more power from grid to reduce fuel consumption.

\section{Conclusions}

A RNGRC includes processes such as raw natural gas purification, $\mathrm{CO}_{2}$ treating, gas compression, blending and liquid recovery processes. The operational planning of such complex RNGRC involves decisions of raw and product streams, stream direction, and load and operating 
parameters of processes and utility systems. We developed a large-scale nonconvex MINLP formulation for optimal planning of such a RNGRC. The planning model includes the stream network, thermodynamics, processes, and utility system. Multiple raw natural gas streams and different product specifications are taken into account in the MINLP formulation. The nonconvex constraints in the MINLP model were reformulated, and the model was solved using the global optimization solvers ANTIGONE and LINGDOGLOBAL in reasonable solution time. The computational results indicate that a significant profit increase of $10.21 \%$ is achieved compared to the present operation of the RNGRC. The compassion between the present and optimal operations shows that the profit can be improved by changing the throughput of raw natural gas $2 \#$, increasing the sale gas for customer $3 \#$, reasonably reducing the production of LPG, and purchasing more power from grid to reduce fuel consumption.

\section{Acknowledgments}

This research is supported by the National Natural Science Foundation of China (No. 21376277) and the project of Guangdong Provincial Natural Science Foundation of China (No. 2015A030313112.

\section{Notation}

\section{Sets/Indices}

$C / c=$ set of chemical components indexed by $c$

$\mathrm{B} / b=$ set of boilers indexed by $b$

$\mathrm{D} / d=$ set of steam turbines indexed by $d$

$S / s=$ set of process streams indexed by $s$

$U / u=$ set of processes indexed by $u$

$B P T_{d}=$ set of back pressure turbines in turbines $D$

$C D T_{d}=$ set of condensing turbines in turbines $D$

$\mathrm{COM}_{u}=$ set of compressors in processes $U$ 
$C S C_{u, c}=$ set of specification of customer $u$ on component $c$

$\mathrm{CUS}_{u}=$ set of customers in processes $U$

$D C T_{u}=$ set of $\mathrm{CO}_{2}$ treating processes in processes $U$

$D E E_{u}=$ set of deethanizers in processes $U$

$D P C_{u}=$ set of dew point controllers in processes $U$

$E D P_{u}=$ set of end processes in processes $U$

$H C D_{u, c}=$ set of heavy component $c$ for stabilizers in processes $U$

$H S_{S}=$ set of heavy streams in streams $S$

$L C D_{u, c}=$ set of light component $c$ for deethanizers and stabilizers in processes $U$

$L S_{S}=$ set of light streams in streams $S$

$P C T_{u}=$ set of plug catchers in processes $U$

$R N G_{u}=$ set of raw natural gas terminals in Processes $U$

$S E P_{u}=$ set of separators in processes $U$

$\operatorname{SFP}_{u, s}=$ set of streams from processes $U$

$S S D_{u, s, u^{\prime}}=$ set of process stream $s$ from process $u$ to $u^{\prime}$

$S T A_{u}=$ set of stabilizers in processes $U$

$V U S_{u}=$ set of utility systems in processes $U$

Parameters

$\alpha=$ relative volatility for deethanizers and stabilizer [dimensionless]

$\beta, \sigma, \psi=$ parameters used in process models [dimensionless]

$\gamma=$ molar density of solvent $\left[\mathrm{kmol} / \mathrm{m}^{3}\right]$

$\delta=$ heat of desorption reaction $[\mathrm{MJ} / \mathrm{kmol}]$

$\varepsilon=$ specific heat capacity $\left[\mathrm{MJ} / \mathrm{kmol} /{ }^{\circ} \mathrm{C}\right]$

$\zeta=$ price $[\$ / \mathrm{kmol} ; \$ / \mathrm{MW} / \mathrm{h}]$

$\eta=$ efficiency [dimensionless]

$\theta=$ isentropic exponent of compressor [dimensionless]

$\iota=$ reflux ratio of regenerator [dimensionless]

$\kappa=$ absorption ability of solvent [dimensionless]

$\lambda=$ blowdown rate of boiler [dimensionless] 


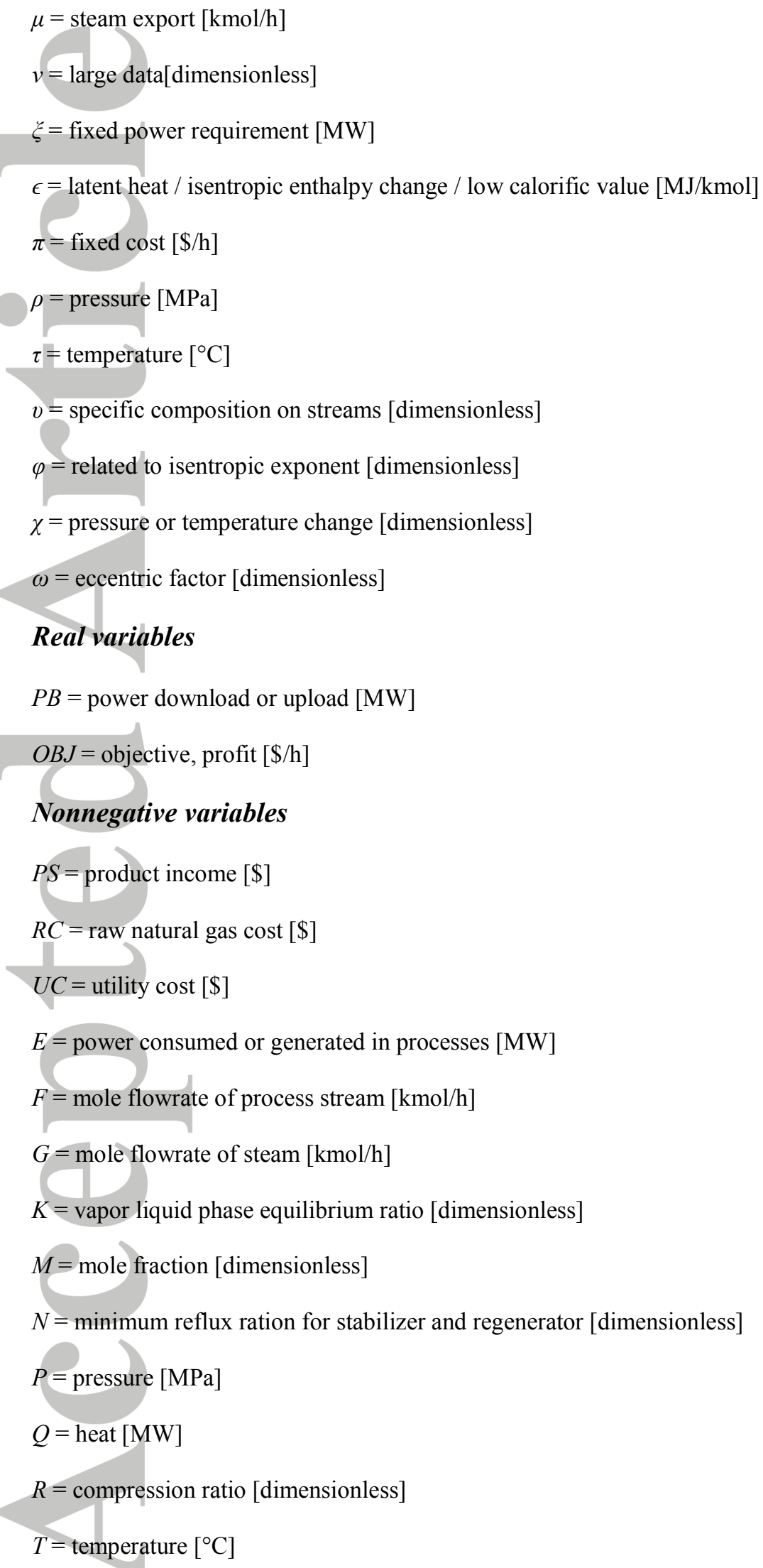




\section{Binary variables}

$X=0,1$ variable $[$ dimensionless $]$

\section{Literature Cited}

1. Floudas, CA, Niziolek AM, Onel O, Matthews LR. Multi-scale systems engineering for energy and the environment: Challenges and opportunities. AIChE J. 2016;62:602-623.

2. Siirola JJ. The impact of shale gas in the chemical industry. AIChE J. 2014;60:810-819.

3. Floudas CA, Elia JA, Baliban RC. Hybrid and single feedstock energy processes for liquid transportation fuels: A critical review. Comput Chem Eng. 2012;41:24-51.

4. Energy Development Strategy Action Plan of China (2014- 2020). Beijing: General Office of the State Council of the People's Republic of China. 2014.

5. Barbosa-Póvoa A. Progresses and challenges in process industry supply chains optimization. Curr Opin Chem Eng. 2012;1:446-452.

6. Grossmann IE. Challenges in the application of mathematical programming in the enterprise-wide optimization of process industries. Theor Found Chem Eng. 2014;8:555-573.

7. Nikolopoulou A, Ierapetritou M. Optimal design of sustainable chemical processes and supply chains: A review. Comput Chem Eng. 2012;44:94-103.

8. Baliban RC, Elia JA, Misener R; Floudas CA. Global optimization of a MINLP process synthesis model for thermochemical based conversion of hybrid coal, biomass, and natural gas to liquid fuels. Comput Chem Eng. 2012;42:64-86.

9. Misener R, Smadbeck JB, Floudas CA. Dynamically generated cutting planes for mixed-integer quadratically constrained quadratic programs and their incorporation into GloMIQO 2. Optim Methods Softw. 2015;30:215-249.

10. Zheng QP, Rebennack S, Iliadis NA, Pardalos PM. Optimization models in the natural gas industry. In: Rebennack S, Pardalos PM, Pereira MV, Iliadis NA. (eds.) Handbook of Power Systems I, chap. 6, 121-148. Springer (2010).

11. Diaz MS, Serrani A, Bandoni JA, Brignole EA. Automatic Design and Optimization of Natural Gas Plants. Ind Eng Chem Res. 1997;36:2715-2724.

12. Selot A, Kuok LK, Robinson M, Mason TL, Barton PI. A Short-Term Operational Planning Model for Natural Gas Production Systems. AIChE J. 2008;54:495-515. 
13. Li X, Armagan E, Tomasgard A, Barton PI. Stochastic pooling problem for natural gas production network design and operation under uncertainty. AIChE J. 2011;57:2120-2135.

14. Tabkhi F, Pibouleau L, Hernandez-Rodriguez G, Azzaro-Pantel C, Domenech S. Improving the performance of natural gas pipeline networks fuel consumption minimization problems. AIChE J. 2010;56: 946-964.

15. Flores-Salazar MA. Vázquez-Román R, Grossmann IE, Iglesias-Silva G. A multiperiod planning model for gas production system. J Petrol Sci Eng. 2011;77:226-235.

16. Baliban RC, Elia JA, Floudas CA. Novel Natural Gas to Liquids Processes: Process Synthesis and Global Optimization Strategies. AIChE J. 2013;59:505-531.

17. Elia JA, Li J; Floudas CA. Strategic planning optimization for natural gas to liquid transportation fuel (GTL) systems. Comput Chem Eng. 2015;72:109-125.

18. Cafaro DC, Grossmann IE. Strategic Planning, Design, and Development of the Shale Gas Supply Chain Network. AIChE J. 2014;60:2122-2142.

19. Gao J, You F. Shale Gas Supply Chain Design and Operations toward Better Economic and Life Cycle Environmental Performance: MINLP Model and Global Optimization Algorithm. Acs Sustain Chem Eng. $2015 ; 3: 1282-1291$.

20. Gao J, You F. Optimal Design and Operations of Supply Chain Networks for Water Management in Shale Gas Production: MILFP Model and Algorithms for the Water-Energy Nexus. AIChE J. 2015;61:1184-1208.

21. Xiong G, Nyberg TR. Push/pull production plan and schedule used in modern refinery CIMS. Comput Chem Eng. 2000;16: 397-410.

22. Wilson, G. A modified Redlich-Kwong equation of state applicable to general physical data calculations. 65th AIChE National meeting, 1968.

23. Hasan MMF, Baliban RC, Elia JA, Floudas CA. Modeling, Simulation, and Optimization of Postcombustion CO2 Capture for Variable Feed Concentration and Flow Rate. 1. Chemical Absorption and Membrane Processes. Ind Eng Chem Res. 2012;51:15642-15664.

24. Mokhatab S, Poe WA, Mak JY. Handbook of Natural Gas Transmission and Processing: principles and practices. Third Edition. MA: Gulf Professional Publishing. 2015.

25. Mofarahi M, Khojasteh $\mathrm{Y}$, Khaledi $\mathrm{H}$, Farahnak A. Design of $\mathrm{CO}_{2}$ absorption plant for recovery of $\mathrm{CO}_{2}$ from flue gases of gas turbine. Energy. 2008;33:1311-1319.

26. Moshfeghian M. Variation of Ideal Gas Heat Capacity Ratio with Temperature and Relative Density (Tip 
of the Month). John M. Campbell \& Co., Norman, OK, USA. May 2013.

27. Branan CR. Rules of thumb for chemical engineers, Third Edition. Amsterdam: Elsevier, 2005.

28. Zhang BJ, Liu K, Luo XL, Chen QL, Li WK. A multi-period mathematical model for simultaneous optimization of materials and energy on the refining site scale. Appl Energ, 2015;143:238-250.

29. Shang ZG, Kokossis AC. A transhipment model for the optimization of steam levels of total site utility system for multiperiod operation. Comput Chem Eng. 2004;28:1673-1688.

30. Mavromatis SP, Kokossis AC. Hardware composites: a new conceptual tool for the analysis and optimization of steam turbine networks in chemical process industries. Part I: principles and construction procedure. Chem Eng Sci. 1998;53:1405-1434.

31. Floudas CA. Nonlinear and Mixed-Integer Optimization: Fundamentals and Applications. New York, NY: Oxford University Press, 1995.

32. Floudas CA. Deterministic Global Optimization: Theory, Methods, and Applications; Nonconvex Optimization and It's Applications. Dordrecht, Netherlands: Kluwer Academic Publishers, 2000.

33. Floudas CA, Gounaris CE. A Review of Recent Advances in Global Optimization. J Global Optim. $2009 ; 45: 3-38$

34. Misener R, Floudas CA. ANTIGONE: Algorithms for coNTinuous / Integer Global Optimization of Nonlinear Equations. J Global Optim. 2014;59:503-526.

35. Sahinidis NV. BARON: A general purpose global optimization software package. J Global Optim. 1996;8:201-205.

36. GAMS - The Solver Manuals. Washington: GAMS Development Corporation, 2015.

\section{Appendix A: Data and solution results for example}




\section{Table captions}

Table 1. Properties of constraints in the model

Table 2. Data for example

Table 3. Solution performance for example

Table A1. Processes and streams in the RNGRC

Table A2. Existing stream network

Table A3. Optimal process capacity and operating parameters

Table A4. Optimal flowrate and composition of process streams

Table A5. Optimal process stream network $(\mathrm{kmol} / \mathrm{h})$

Table A6. Optimal result of utility system

Table A7. Present operation in the RNGRC

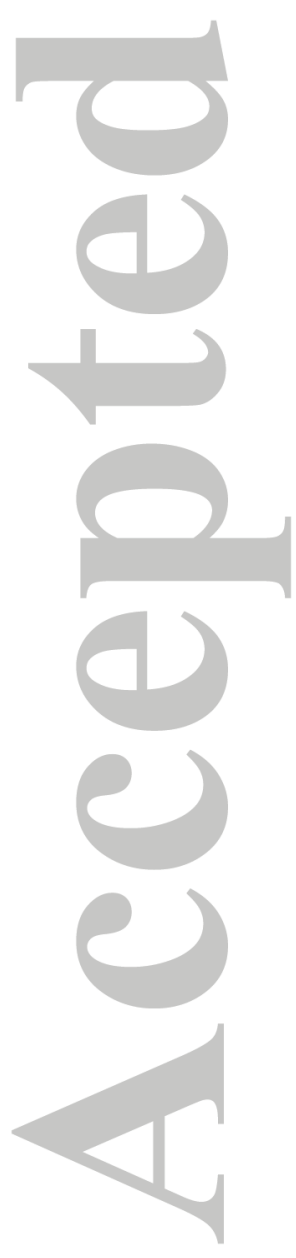


Table 1. Properties of constraints in the model

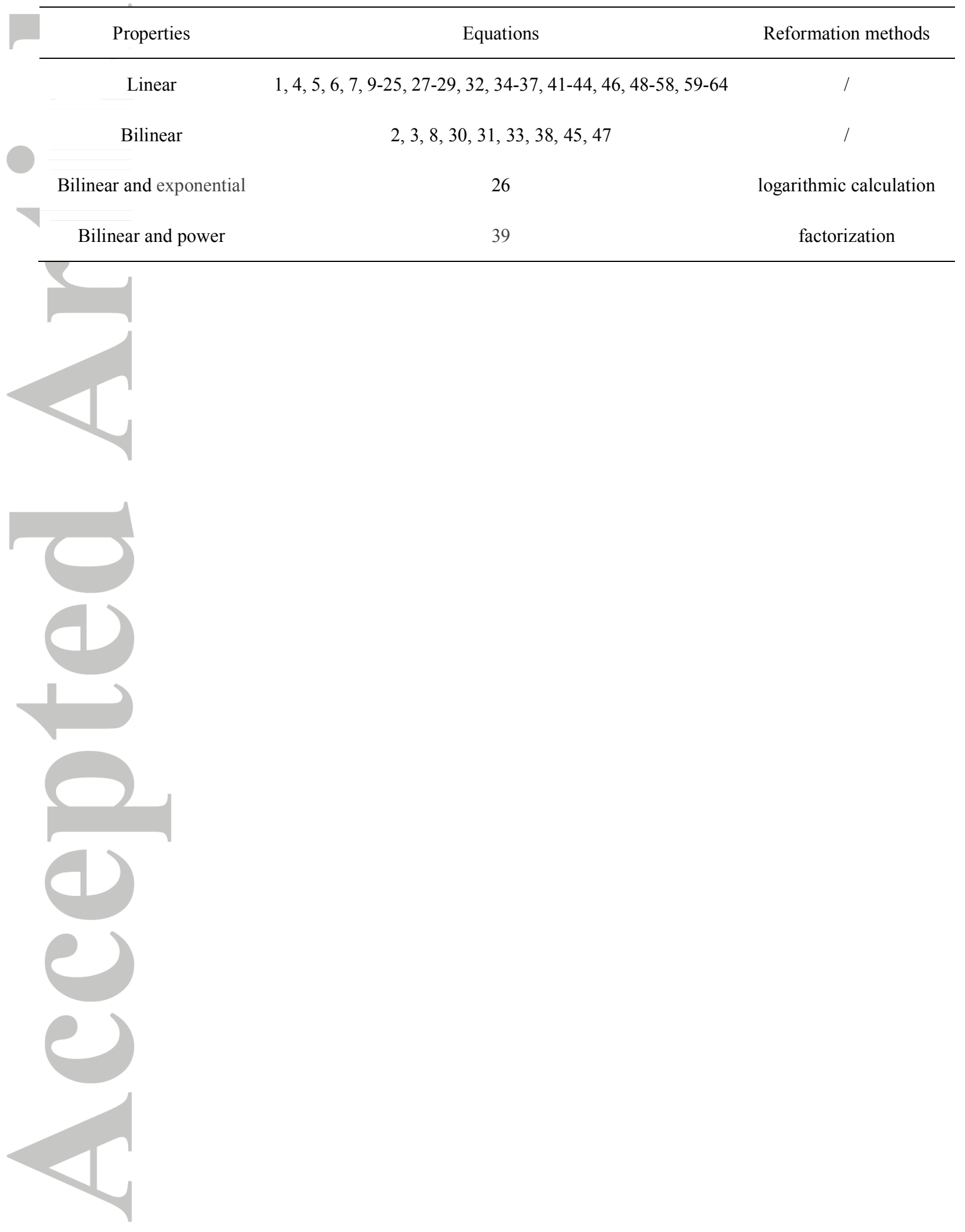




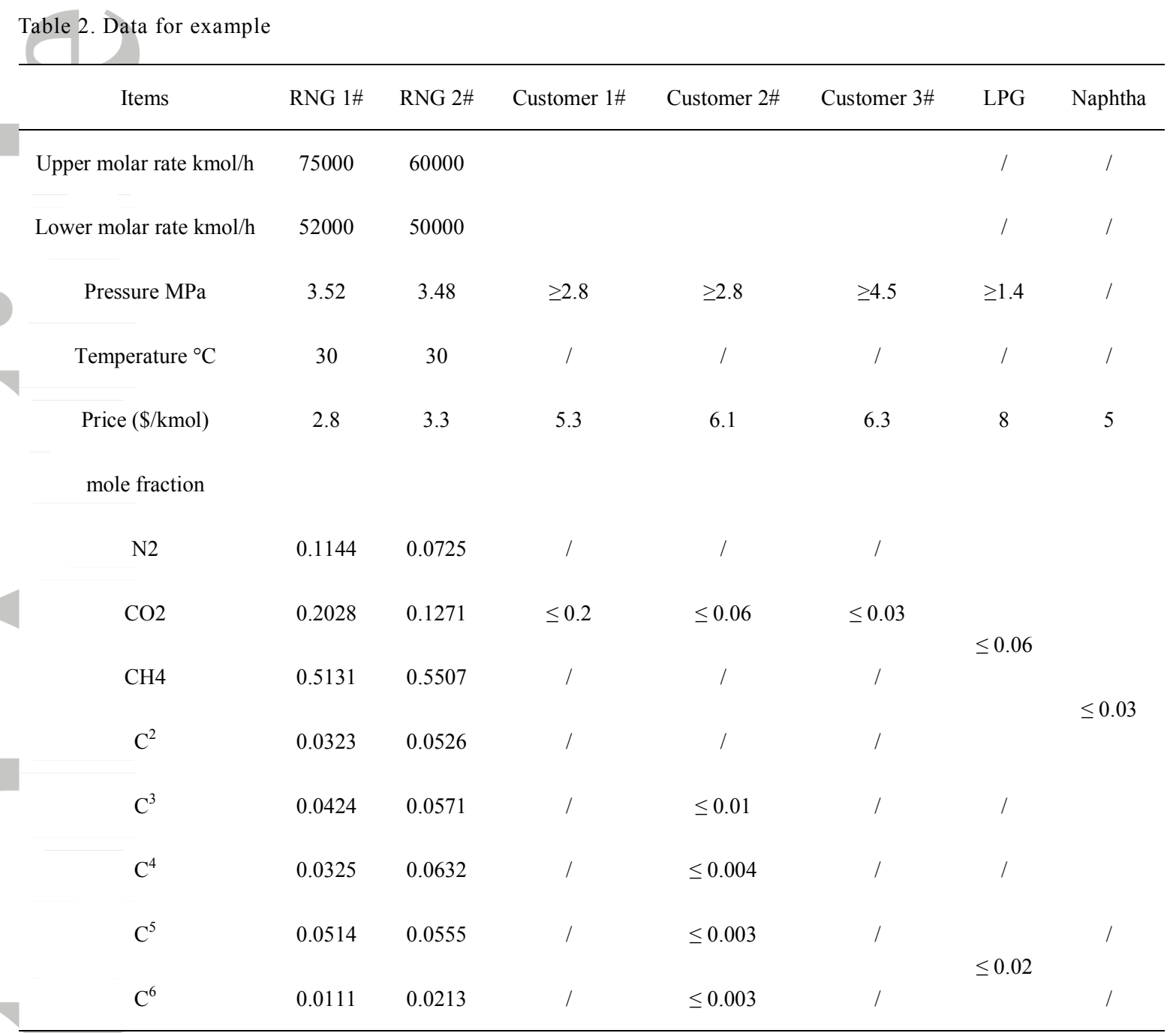


Table 3. Solution performance for example

\begin{tabular}{|c|c|c|c|c|c|}
\hline Solvers & Solver status & $\begin{array}{l}\text { Model } \\
\text { status }\end{array}$ & $\begin{array}{c}\text { Executive } \\
\text { Time (second) }\end{array}$ & $\begin{array}{c}\text { Lower } \\
\text { bound (\$) }\end{array}$ & $\begin{array}{c}\text { Upper } \\
\text { bound (\$) }\end{array}$ \\
\hline ANTIGONE & Normal completion & Integer solution & 146 & 291,040 & 293951 \\
\hline BARON & Iteration Interrupt & No feasible solution* & 360,000 & $*$ & $*$ \\
\hline LINDOGLOBAL & Normal completion & Integer solution & 372 & 286,433 & 289300 \\
\hline
\end{tabular}

*: No feasible solution found after 360,000 seconds.
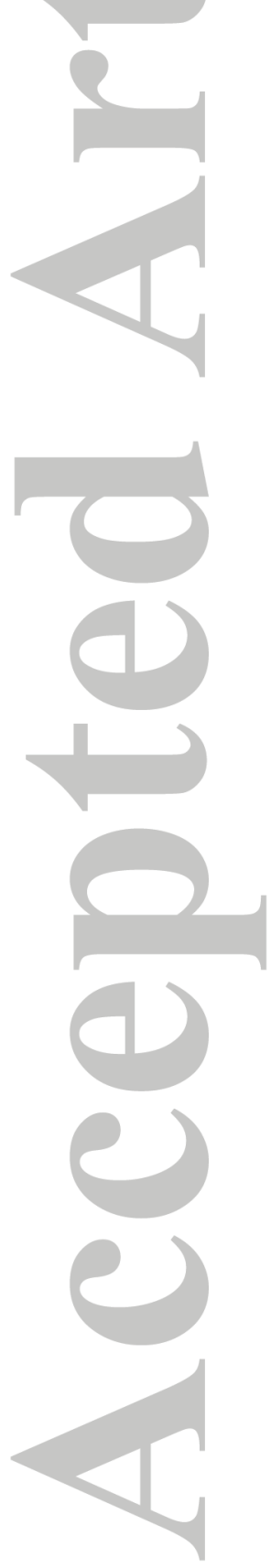


\begin{tabular}{|c|c|c|c|}
\hline Process name & Process number & Code of process node & Stream exiting process \\
\hline Subsea terminal & 2 & SNOD1 & G0 \\
\hline Plug catcher & 3 & SPCA1-SPCA3 & G1 (light stream), L1 (heavy stream) \\
\hline Dew point controller & 3 & SPDC1- SPDC3 & G2 (light stream), L2 (heavy stream) \\
\hline Treating process & 3 & SMDE1-SMDE3 & GA (gas), GE (carbon dioxide) \\
\hline Dehydration & 3 & SDEH1-SDEH3 & GB \\
\hline Compression & 3 & SCOM1-SCOM3 & $\mathrm{GC}$ \\
\hline Pipe Blending & 3 & SPLE1-SPLE3 & GD \\
\hline Separator & 3 & SSEP1-SSEP3 & G3 (light stream), L3 (heavy stream) \\
\hline Deethanizer & 3 & SDEE1-SDEE3 & G4 (light stream), L4 (heavy stream) \\
\hline Stabilizer & 3 & SSTA1-SSTA3 & G5 (light stream), L5 (heavy stream) \\
\hline $\mathrm{CO}_{2}$ product & 1 & ECAR & / \\
\hline Gas customer & 3 & ENOD1-ENOD & l \\
\hline LPG product & 1 & ELPG & l \\
\hline Naphtha product & 1 & ENAP & / \\
\hline Utility system & 1 & SUTIL & l \\
\hline
\end{tabular}

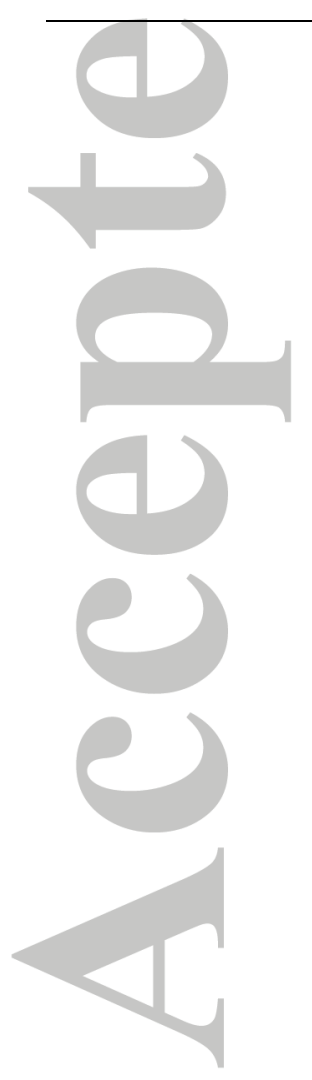




\begin{tabular}{|c|c|c|c|c|c|c|c|c|}
\hline Resource & Stream & destination & Resource & Stream & destination & Resource & Stream & destination \\
\hline SNOD1 & G0 & SPCA1 & SPCA2 & G1 & SUTIL & SDEH3 & GB & SCOM3 \\
\hline SNOD1 & G0 & SPCA2 & SPCA3 & G1 & SUTIL & SDEH1 & GB & SPLE1 \\
\hline SNOD1 & G0 & SPCA3 & SDPC1 & G2 & SMDE1 & SDEH1 & GB & SPLE2 \\
\hline SNOD2 & G0 & SPCA1 & SDPC1 & G2 & SCOM1 & SDEH1 & GB & SPLE3 \\
\hline SNOD2 & G0 & SPCA2 & SDPC1 & G2 & SPLE1 & SDEH2 & GB & SPLE1 \\
\hline SNOD2 & G0 & SPCA3 & SDPC1 & G2 & SPLE2 & SDEH2 & GB & SPLE2 \\
\hline SPCA1 & G1 & SDPC1 & SDPC1 & G2 & SPLE3 & SDEH2 & GB & SPLE3 \\
\hline SPCA1 & G1 & SCOM1 & SDPC1 & L2 & SSEP1 & SDEH3 & GB & SPLE1 \\
\hline SPCA1 & G1 & SPLE1 & SDPC1 & G2 & SMDE2 & SDEH3 & GB & SPLE2 \\
\hline SPCA1 & G1 & SPLE2 & SDPC1 & G2 & SMDE3 & SDEH3 & GB & SPLE3 \\
\hline SPCA1 & G1 & SPLE3 & SDPC1 & L2 & SSEP2 & SCOM1 & $\mathrm{GC}$ & SPLE1 \\
\hline SPCA1 & L1 & SSEP1 & SDPC1 & L2 & SSEP3 & SCOM1 & $\mathrm{GC}$ & SPLE2 \\
\hline SPCA1 & G1 & SDPC2 & SDPC2 & G2 & SMDE2 & SCOM1 & $\mathrm{GC}$ & SPLE3 \\
\hline SPCA1 & G1 & SDPC3 & SDPC2 & G2 & SCOM2 & SCOM2 & $\mathrm{GC}$ & SPLE1 \\
\hline SPCA1 & L1 & SSEP2 & $\mathrm{SDPC} 2$ & G2 & SPLE1 & SCOM2 & $\mathrm{GC}$ & SPLE2 \\
\hline SPCA1 & L1 & SSEP3 & SDPC2 & G2 & SPLE2 & SCOM2 & $\mathrm{GC}$ & SPLE3 \\
\hline SPCA2 & G1 & SDPC2 & SDPC2 & G2 & SPLE3 & SCOM3 & $\mathrm{GC}$ & SPLE1 \\
\hline SPCA2 & G1 & SCOM2 & SDPC2 & L2 & SSEP2 & SCOM3 & $\mathrm{GC}$ & SPLE2 \\
\hline SPCA2 & G1 & SPLE1 & SDPC2 & G2 & SMDE1 & SCOM3 & $\mathrm{GC}$ & SPLE3 \\
\hline SPCA2 & G1 & SPLE2 & SDPC2 & G2 & SMDE3 & SPLE1 & GD & ENOD1 \\
\hline SPCA2 & G1 & SPLE3 & SDPC2 & L2 & SSEP1 & SPLE2 & GD & ENOD2 \\
\hline SPCA2 & $\mathrm{L} 1$ & SSEP2 & SDPC2 & L2 & SSEP3 & SPLE3 & GD & ENOD3 \\
\hline SPCA2 & G1 & SDPC1 & SDPC3 & G2 & SMDE3 & SSEP1 & L3 & SDEE1 \\
\hline SPCA2 & G1 & SDPC3 & SDPC3 & G2 & SCOM3 & SSEP1 & G3 & SUTIL \\
\hline SPCA2 & $\mathrm{L} 1$ & SSEP1 & SDPC3 & G2 & SPLE1 & SSEP2 & L3 & SDEE2 \\
\hline SPCA2 & $\mathrm{L} 1$ & SSEP3 & SDPC3 & G2 & SPLE2 & SSEP2 & G3 & SUTIL \\
\hline SPCA3 & G1 & SDPC3 & SDPC3 & G2 & SPLE3 & SSEP3 & L3 & SDEE3 \\
\hline SPCA3 & G1 & SCOM3 & SDPC3 & L2 & SSEP3 & SSEP3 & G3 & SUTIL \\
\hline SPCA3 & G1 & SPLE1 & SDPC3 & G2 & SMDE1 & SDEE1 & L4 & SSTA1 \\
\hline SPCA3 & G1 & SPLE2 & SDPC3 & G2 & SMDE2 & SDEE1 & G4 & SUTIL \\
\hline SPCA3 & G1 & SPLE3 & SDPC3 & L2 & SSEP1 & SDEE2 & L4 & SSTA2 \\
\hline SPCA3 & $\mathrm{L} 1$ & SSEP3 & SDPC3 & L2 & SSEP2 & SDEE2 & G4 & SUTIL \\
\hline SPCA3 & G1 & SDPC1 & SMDE1 & GA & SDEH1 & SDEE3 & L4 & SSTA3 \\
\hline SPCA3 & G1 & SDPC2 & SMDE2 & GA & SDEH2 & SDEE3 & G4 & SUTIL \\
\hline SPCA3 & $\mathrm{L} 1$ & SSEP1 & SMDE3 & GA & SDEH3 & SSTA1 & G5 & ELPG \\
\hline SPCA3 & $\mathrm{L} 1$ & SSEP2 & SMDE1 & GE & ECAR & SSTA1 & L5 & ENAP \\
\hline SPCA1 & G1 & SMDE1 & SMDE2 & GE & ECAR & SSTA2 & G5 & ELPG \\
\hline SPCA2 & G1 & SMDE2 & SMDE3 & GE & ECAR & SSTA2 & L5 & ENAP \\
\hline SPCA3 & G1 & SMDE3 & SDEH1 & GB & SCOM1 & SSTA3 & G5 & ELPG \\
\hline SPCA1 & G1 & SUTIL & SDEH2 & GB & SCOM2 & SSTA3 & L5 & ENAP \\
\hline
\end{tabular}


Table A3. Optimal process capacity and operating parameters

\begin{tabular}{|c|c|c|c|c|c|}
\hline Process & Capacity kmol/h & Temperature $\mathrm{K}$ & Temperature change $\mathrm{K}$ & Pressure $\mathrm{MPa}$ & Pressure change $\mathrm{MPa}$ \\
\hline SNOD1 & 75000 & / & 1 & 3.52 & / \\
\hline SNOD2 & 60000 & l & / & 3.48 & / \\
\hline SPCA1 & 30000 & 303.15 & 0 & 3.48 & l \\
\hline SPCA2 & 55000 & 303.15 & 0 & 3.48 & l \\
\hline SPCA3 & 50000 & 303.15 & 0 & 3.48 & l \\
\hline SDPC1 & 25004 & 303.15 & 17.123 & 3.48 & / \\
\hline SDPC2 & 33255 & 303.15 & 0 & 3.48 & l \\
\hline SDPC3 & 29085 & 303.15 & 59.431 & 3.48 & l \\
\hline SMDE1 & 0 & l & / & 2.8 & l \\
\hline SMDE2 & 57704 & l & / & 3.48 & / \\
\hline SMDE3 & 16996 & l & l & 2.8 & l \\
\hline SDEH1 & 0 & I & l & 2.8 & 1 \\
\hline SDEH2 & 50000 & l & / & 3.48 & I \\
\hline SDEH3 & 14082 & I & I & 2.8 & I \\
\hline SCOM1 & 0 & I & I & 2.8 & 0 \\
\hline SCOM2 & 50000 & I & I & 3.48 & 1.02 \\
\hline SCOM3 & 0 & I & I & 2.8 & 0 \\
\hline SSEP1 & 7719 & 303.15 & 0 & 3.48 & I \\
\hline SSEP2 & 15000 & 303.15 & 0 & 3.48 & I \\
\hline SSEP3 & 0 & 303.15 & 0 & 3.48 & I \\
\hline SDEE1 & 7353 & I & I & 1.4 & I \\
\hline SDEE2 & 14062 & I & I & 1.4 & I \\
\hline SDEE3 & 0 & I & I & 1.4 & I \\
\hline SSTA1 & 5861 & I & / & 1.4 & I \\
\hline SSTA2 & 10937 & I & I & 1.4 & I \\
\hline SSTA3 & 0 & I & / & 1.4 & / \\
\hline SPLE1 & 30000 & I & I & 2.8 & I \\
\hline SPLE2 & 21663 & I & / & 2.8 & / \\
\hline SPLE3 & 50000 & I & I & 4.5 & I \\
\hline SUTIL & 5921 & I & I & I & I \\
\hline ENOD1 & 30000 & I & I & 2.8 & I \\
\hline ENOD2 & 21663 & I & I & 2.8 & I \\
\hline ENOD3 & 50000 & I & I & 4.5 & I \\
\hline ELPG & 8362 & I & I & 1.4 & I \\
\hline ENAP & 8437 & I & I & I & I \\
\hline ECAR & 10618 & I & / & / & I \\
\hline
\end{tabular}

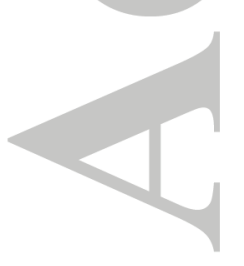

46

AIChE Journal

This article is protected by copyright. All rights reserved. 
Table A4. Optimal flowrate and composition of process streams

\begin{tabular}{|c|c|c|c|c|c|c|c|c|c|}
\hline \multirow{2}{*}{ Streams } & \multirow{2}{*}{ Flowrate $\mathrm{kmol} / \mathrm{h}$} & \multicolumn{8}{|c|}{ Mole composition } \\
\hline & & $\mathrm{N}_{2}$ & $\mathrm{CO}_{2}$ & $\mathrm{CH}_{4}$ & $\mathrm{C}_{2} \mathrm{H}_{6}$ & $\mathrm{C}_{3} \mathrm{H}_{8}$ & $\mathrm{C}_{4} \mathrm{H}_{10}$ & $\mathrm{C}_{5} \mathrm{H}_{12}$ & $\mathrm{C}_{6} \mathrm{H}_{14}$ \\
\hline SNOD1.G0 & 75000 & 0.114 & 0.203 & 0.513 & 0.032 & 0.042 & 0.033 & 0.051 & 0.011 \\
\hline SNOD2.G0 & 60000 & 0.073 & 0.127 & 0.551 & 0.053 & 0.057 & 0.063 & 0.056 & 0.021 \\
\hline SPCA1.G1 & 25004 & 0.086 & 0.139 & 0.648 & 0.055 & 0.042 & 0.022 & 0.007 & 0.001 \\
\hline SPCA1.L1 & 4996 & 0.003 & 0.067 & 0.065 & 0.041 & 0.134 & 0.269 & 0.297 & 0.123 \\
\hline SPCA2.G1 & 47470 & 0.105 & 0.174 & 0.609 & 0.045 & 0.039 & 0.019 & 0.008 & 0.001 \\
\hline SPCA2.L1 & 7530 & 0.004 & 0.084 & 0.061 & 0.033 & 0.124 & 0.237 & 0.340 & 0.116 \\
\hline SPCA3.G1 & 44870 & 0.127 & 0.214 & 0.565 & 0.033 & 0.035 & 0.015 & 0.010 & 0.001 \\
\hline SPCA3.L1 & 5130 & 0.005 & 0.103 & 0.057 & 0.025 & 0.111 & 0.185 & 0.414 & 0.101 \\
\hline SDPC1.G2 & 24448 & 0.088 & 0.140 & 0.661 & 0.055 & 0.038 & 0.015 & 0.003 & 0.000 \\
\hline SDPC1.L2 & 556 & 0.004 & 0.100 & 0.082 & 0.058 & 0.193 & 0.320 & 0.206 & 0.037 \\
\hline SDPC3.G2 & 24577 & 0.145 & 0.171 & 0.648 & 0.026 & 0.009 & 0.001 & 0.000 & 0.000 \\
\hline SDPC3.L2 & 4508 & 0.010 & 0.414 & 0.151 & 0.083 & 0.179 & 0.096 & 0.062 & 0.005 \\
\hline SMDE2.GA & 50000 & 0.113 & 0.030 & 0.728 & 0.057 & 0.045 & 0.020 & 0.007 & 0.001 \\
\hline SMDE2.GE & 7704 & 0.000 & 1.000 & 0.000 & 0.000 & 0.000 & 0.000 & 0.000 & 0.000 \\
\hline SMDE3.GA & 14082 & 0.175 & 0.000 & 0.782 & 0.031 & 0.011 & 0.001 & 0.000 & 0.000 \\
\hline SMDE3.GE & 2914 & 0.000 & 1.000 & 0.000 & 0.000 & 0.000 & 0.000 & 0.000 & 0.000 \\
\hline SDEH2.GB & 50000 & 0.113 & 0.030 & 0.728 & 0.057 & 0.045 & 0.020 & 0.007 & 0.001 \\
\hline SDEH3.GB & 14082 & 0.175 & 0.000 & 0.782 & 0.031 & 0.011 & 0.001 & 0.000 & 0.000 \\
\hline SCOM2.GC & 50000 & 0.113 & 0.030 & 0.728 & 0.057 & 0.045 & 0.020 & 0.007 & 0.001 \\
\hline SSEP1.G3 & 366 & 0.054 & 0.252 & 0.556 & 0.063 & 0.047 & 0.021 & 0.007 & 0.001 \\
\hline SSEP1.L3 & 7353 & 0.002 & 0.121 & 0.056 & 0.047 & 0.149 & 0.252 & 0.270 & 0.102 \\
\hline SSEP2.G3 & 938 & 0.058 & 0.316 & 0.505 & 0.054 & 0.043 & 0.016 & 0.008 & 0.001 \\
\hline SSEP2.L3 & 14061 & 0.002 & 0.152 & 0.051 & 0.040 & 0.137 & 0.200 & 0.325 & 0.093 \\
\hline SDEE1.G4 & 1491 & 0.003 & 0.598 & 0.167 & 0.233 & 0.000 & 0.000 & 0.000 & 0.000 \\
\hline SDEE1.L4 & 5861 & 0.002 & 0.000 & 0.028 & 0.000 & 0.187 & 0.316 & 0.339 & 0.128 \\
\hline SDEE2.G4 & 3125 & 0.004 & 0.684 & 0.229 & 0.082 & 0.000 & 0.000 & 0.000 & 0.000 \\
\hline SDEE2.L4 & 10937 & 0.002 & 0.000 & 0.000 & 0.028 & 0.176 & 0.257 & 0.417 & 0.119 \\
\hline SSTA1.G5 & 3188 & 0.004 & 0.000 & 0.051 & 0.000 & 0.343 & 0.582 & 0.020 & 0.000 \\
\hline SSTA1.L5 & 2673 & 0.000 & 0.000 & 0.000 & 0.000 & 0.000 & 0.000 & 0.720 & 0.280 \\
\hline SSTA2.G5 & 5174 & 0.004 & 0.000 & 0.000 & 0.060 & 0.373 & 0.544 & 0.020 & 0.000 \\
\hline SSTA2.L5 & 5763 & 0.000 & 0.000 & 0.000 & 0.000 & 0.000 & 0.000 & 0.774 & 0.226 \\
\hline SPLE1.GD & 30000 & 0.119 & 0.200 & 0.580 & 0.037 & 0.036 & 0.017 & 0.009 & 0.001 \\
\hline SPLE2.GD & 21663 & 0.165 & 0.060 & 0.735 & 0.029 & 0.010 & 0.001 & 0.000 & 0.000 \\
\hline SPLE3.GD & 50000 & 0.113 & 0.030 & 0.728 & 0.057 & 0.045 & 0.020 & 0.007 & 0.001 \\
\hline
\end{tabular}


Table A5. Optimal process stream network $(\mathrm{kmol} / \mathrm{h})$

\begin{tabular}{|c|c|c|c|c|c|c|c|c|c|c|c|c|c|c|c|c|}
\hline & SPCA1 & SPCA2 & SPCA3 & SDPC1 & SDPC2 & SDPC3 & SMDE1 & SMDE2 & SMDE3 & SDEH1 & SDEH2 & SDEH3 & SCOM1 & SCOM2 & SCOM3 & \\
\hline SNOD1 & 0 & 25000 & 50000 & 1 & 1 & 1 & 1 & 1 & 1 & 1 & 1 & 1 & 1 & 1 & 1 & \\
\hline SNOD2 & 30000 & 30000 & 0 & 1 & I & I & I & I & I & I & I & / & I & I & 1 & \\
\hline SPCA1 & & I & I & 25004 & 0 & 0 & 0 & I & I & 1 & 1 & I & 0 & I & 1 & \\
\hline SPCA2 & 1 & I & I & 0 & 0 & 3665 & I & 33255 & 1 & 1 & I & I & I & 0 & 1 & \\
\hline SPCA3 & 1 & I & I & 0 & 0 & 25419 & I & 1 & 0 & 1 & 1 & I & I & I & 0 & \\
\hline SDPC1 & 1 & I & I & 1 & 1 & I & 0 & 24448 & 0 & 1 & 1 & I & 0 & I & 1 & \\
\hline SDPC2 & I & I & I & 1 & 1 & I & 0 & 0 & 0 & 1 & I & I & I & 0 & 1 & \\
\hline SDPC3 & 1 & I & I & 1 & 1 & I & 0 & 0 & 16996 & I & I & / & I & I & 0 & \\
\hline SMDE2 & I & I & I & 1 & 1 & / & I & 1 & I & I & 50000 & / & I & 1 & 1 & \\
\hline SMDE3 & I & I & I & 1 & 1 & I & I & I & 1 & 1 & I & 14082 & I & I & 1 & \\
\hline SDEH2 & 1 & I & I & 1 & 1 & I & I & 1 & 1 & 1 & 1 & I & I & 50000 & 1 & \\
\hline SDEH3 & 1 & 1 & 1 & 1 & 1 & 1 & 1 & 1 & 1 & 1 & 1 & 1 & 1 & 1 & 0 & \\
\hline & SSEP1 & SSEP2 & SDEE1 & SDEE2 & SSTA1 & SSTA2 & SPLE1 & SPLE2 & SPLE3 & SUTIL & ENOD1 & ENOD2 & ENOD3 & ELPG & ENAP & ECAR \\
\hline
\end{tabular}

\begin{tabular}{|c|c|c|c|c|c|c|c|c|c|c|c|c|c|c|c|c|}
\hline & SSEP1 & SSEP2 & SDEE1 & SDEE2 & SSTA1 & SSTA2 & SPLE1 & SPLE2 & SPLE3 & SUTIL & ENOD1 & ENOD2 & ENOD3 & ELPG & ENAP & ECAR \\
\hline SPCA1 & 4996 & 0 & 1 & 1 & 1 & 1 & 0 & 0 & 0 & 0 & 1 & 1 & 1 & 1 & 1 & 1 \\
\hline SPCA2 & 922 & 6608 & I & I & I & I & 10550 & 0 & 0 & 0 & 1 & I & 1 & 1 & I & I \\
\hline SPCA3 & 0 & 5130 & I & 1 & 1 & I & 19450 & 0 & 0 & 0 & 1 & I & 1 & I & 1 & I \\
\hline SDPC1 & 556 & 0 & I & I & I & I & 0 & 0 & 0 & I & I & I & 1 & I & I & I \\
\hline SDPC2 & 0 & 0 & I & 1 & 1 & I & 0 & 0 & 0 & I & I & I & I & I & 1 & I \\
\hline SDPC3 & 1246 & 3262 & I & 1 & 1 & I & 0 & 7580 & 0 & I & I & I & 1 & I & 1 & I \\
\hline SMDE2 & 1 & I & I & I & I & I & 1 & 1 & I & I & I & I & 1 & I & I & 7704 \\
\hline SMDE3 & 1 & I & I & 1 & 1 & I & I & 1 & I & I & I & I & I & I & 1 & 2914 \\
\hline SDEH2 & 1 & I & I & I & 1 & I & 0 & 0 & 0 & 1 & 1 & 1 & 1 & I & 1 & 1 \\
\hline SDEH3 & 1 & I & I & 1 & 1 & I & 0 & 14082 & 0 & I & I & I & 1 & I & 1 & I \\
\hline SCOM2 & I & I & I & I & I & I & 0 & 0 & 50000 & I & I & I & 1 & I & I & I \\
\hline SSEP1 & I & 1 & 7353 & I & 1 & I & I & 1 & I & 366 & I & I & 1 & I & I & I \\
\hline SSEP2 & 1 & I & & 14061 & 1 & I & I & 1 & 1 & 938 & I & I & I & I & 1 & I \\
\hline SDEE1 & 1 & I & I & 1 & 5861 & I & I & 1 & 1 & 1491 & 1 & I & I & I & 1 & I \\
\hline SDEE2 & I & I & I & 1 & 1 & 10937 & I & I & 1 & 3124 & I & I & I & I & I & I \\
\hline SSTA1 & 1 & I & I & 1 & 1 & 1 & I & 1 & 1 & I & I & I & I & 3188 & 2673 & I \\
\hline SSTA2 & 1 & I & I & I & 1 & I & I & 1 & I & I & I & I & 1 & 5173 & 5763 & I \\
\hline SPLE1 & I & I & I & I & I & I & I & 1 & I & I & 30000 & 1 & 1 & I & 1 & I \\
\hline SPLE2 & I & 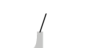 & I & I & 1 & I & I & 1 & I & 1 & 1 & 21662 & I & I & 1 & 1 \\
\hline SPLE3 & 1 & 1 & 1 & 1 & 1 & 1 & 1 & 1 & 1 & 1 & 1 & 1 & 50000 & 1 & 1 & 1 \\
\hline
\end{tabular}




\begin{tabular}{|c|c|c|c|c|c|c|c|}
\hline \multirow{2}{*}{ Process } & \multirow{2}{*}{$\begin{array}{l}\text { Heat duties } \\
\qquad \mathrm{MJ} / \mathrm{h}\end{array}$} & \multicolumn{2}{|c|}{ High pressure steam $\mathrm{kmol} / \mathrm{h}$} & \multicolumn{2}{|c|}{ Low pressure steam $\mathrm{kmol} / \mathrm{h}$} & \multicolumn{2}{|c|}{ Power MW } \\
\hline & & Production & Consumption & Production & Consumption & Production & Consumption \\
\hline Boiler A & 620570 & 8990 & / & l & l & / & / \\
\hline Boiler $\mathrm{E}$ & 189050 & 2674 & l & l & / & l & / \\
\hline Boiler C & 414170 & 6000 & l & l & l & / & / \\
\hline Turbine A & / & 1 & 10089 & 10089 & l & 24 & / \\
\hline Turbine B & l & l & 7575 & 7575 & / & 18 & / \\
\hline Turbine $\mathrm{C}$ & 1 & / & / & l & 0 & 0 & / \\
\hline Turbine D & / & I & I & I & 0 & 0 & / \\
\hline SDPC1 & / & l & / & l & / & / & 1.957 \\
\hline SDPC2 & 1 & 1 & I & l & l & I & 0 \\
\hline SDPC3 & I & I & / & I & I & I & 9.474 \\
\hline SMDE1 & 0 & / & I & 1 & 0 & I & 0 \\
\hline SMDE2 & 125720 & / & / & / & 3343 & / & 1.157 \\
\hline SMDE3 & 41617 & 1 & / & 1 & 1107 & I & 0.421 \\
\hline $\mathrm{SCOM}$ & I & I & I & I & 0 & I & 0 \\
\hline SCOM2 & I & I & / & 1 & 0 & I & 120.111 \\
\hline SCOM3 & I & I & / & I & 0 & / & 0 \\
\hline SDEE1 & 20513 & 1 & I & / & 545 & / & / \\
\hline SDEE2 & 31330 & I & / & l & 833 & I & / \\
\hline SDEE3 & 0 & I & I & / & 0 & / & / \\
\hline SSAT1 & 152740 & l & I & I & 4061 & I & I \\
\hline SSAT2 & 292410 & I & I & I & 7775 & I & I \\
\hline SSAT3 & 0 & I & / & I & 0 & / & / \\
\hline
\end{tabular}


Table A7. Present operation in the RNGRC

\begin{tabular}{|c|c|c|c|c|c|}
\hline Process & Capacity kmol/h & Temperature $\mathrm{K}$ & Temperature change $\mathrm{K}$ & Pressure $\mathrm{MPa}$ & Pressure change $\mathrm{MPa}$ \\
\hline SNOD1 & 75000 & I & 1 & 3.52 & l \\
\hline SNOD2 & 52100 & l & l & 3.48 & l \\
\hline SPCA1 & 0 & 303.15 & 0 & 3.48 & l \\
\hline SPCA2 & 80000 & 303.15 & 0 & 3.48 & l \\
\hline SPCA3 & 47100 & 303.15 & 0 & 3.48 & l \\
\hline SDPC1 & 30000 & 303.15 & 27.69 & 3.48 & l \\
\hline SDPC2 & 20854 & 303.15 & 60.25 & 3.48 & l \\
\hline SDPC3 & 42173 & 303.15 & 52.64 & 3.48 & l \\
\hline SMDE1 & 0 & l & l & 3.48 & l \\
\hline SMDE2 & 28814 & l & l & 3.48 & l \\
\hline SMDE3 & 17521 & 1 & 1 & 3.48 & l \\
\hline SDEH1 & 0 & l & / & 3.48 & l \\
\hline SDEH2 & 23852 & l & / & 3.48 & l \\
\hline SDEH3 & 14482 & l & I & 3.48 & I \\
\hline SCOM1 & 0 & I & / & 3.48 & 0 \\
\hline SCOM2 & 23852 & I & / & 3.48 & 1.02 \\
\hline SCOM3 & 0 & / & I & 3.48 & 0 \\
\hline SSEP1 & 11889 & 303.15 & 0 & 3.48 & I \\
\hline SSEP2 & 13875 & 303.15 & 0 & 3.48 & I \\
\hline SSEP3 & 0 & 303.15 & 0 & 3.48 & I \\
\hline SDEE1 & 10834 & I & / & 1.4 & I \\
\hline SDEE2 & 12547 & I & I & 1.4 & I \\
\hline SDEE3 & 0 & / & I & 1.4 & I \\
\hline SSTA1 & 8278 & / & I & 1.4 & / \\
\hline SSTA2 & 9577 & I & I & 1.4 & / \\
\hline SSTA3 & 0 & 1 & I & 1.4 & I \\
\hline SPLE1 & 55000 & 1 & I & 2.8 & / \\
\hline SPLE2 & 14482 & I & I & 2.8 & I \\
\hline SPLE3 & 23852 & / & I & 4.5 & I \\
\hline SUTIL & 7909 & I & 1 & / & I \\
\hline ENOD1 & 55000 & / & I & 2.8 & I \\
\hline ENOD2 & 14482 & / & 1 & 2.8 & I \\
\hline ENOD3 & 23852 & I & I & 4.5 & I \\
\hline ELPG & 9620 & I & I & 1.4 & / \\
\hline ENAP & 8235 & I & I & I & / \\
\hline ECAR & 8001 & I & I & I & I \\
\hline
\end{tabular}

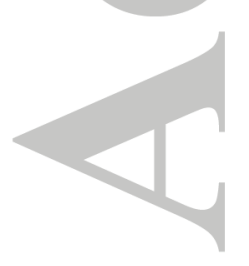




\section{Figure captions}

Figure 1. A simplified diagram of a typical RNGRC.

Figure 2. Nodes and stream network for a plug catcher.

Figure 3. Nodes and stream network for a process.

Figure 4. Schematic diagram of $\mathrm{CO}_{2}$ treating process.

Figure 5. Schematic diagram of the utility system.

Figure 6. Best molecular flow chart from raw natural gas to products.

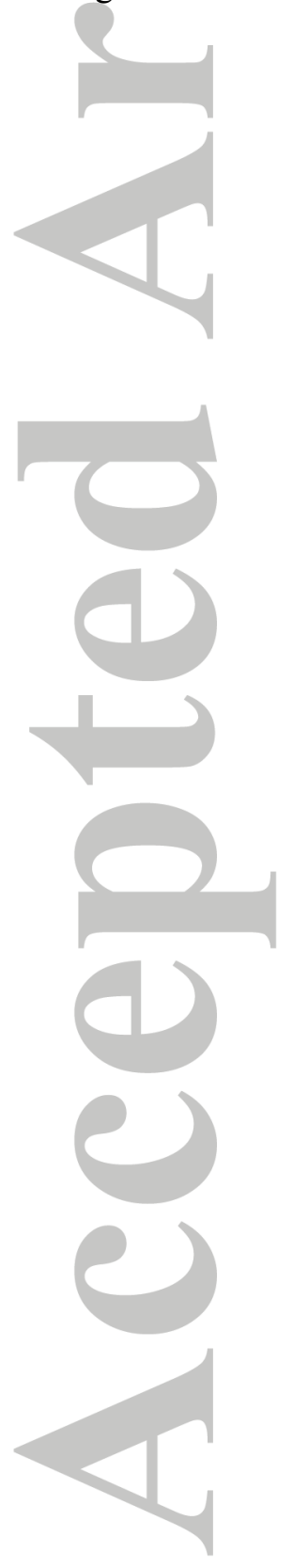




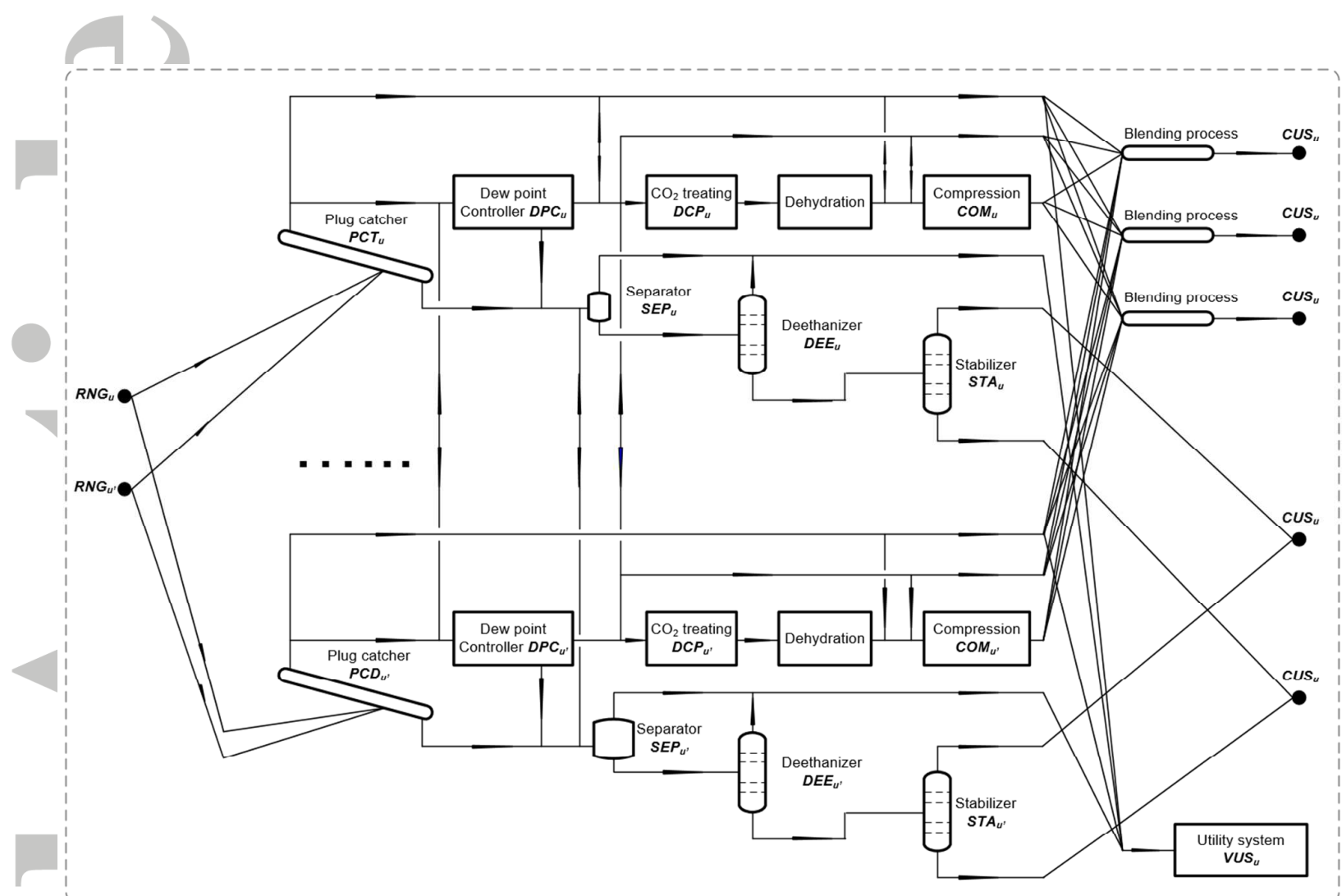

Figure 1. A simplified diagram of a typical RNGRC. 


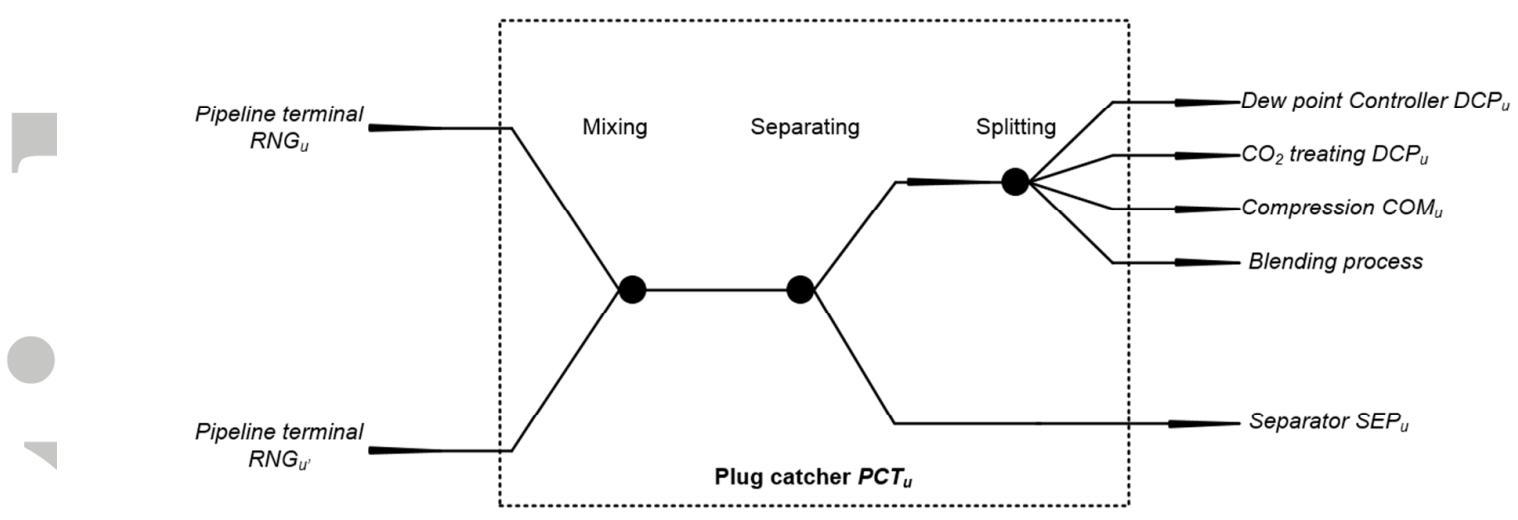

Figure 2. Nodes and stream network for a plug catcher.
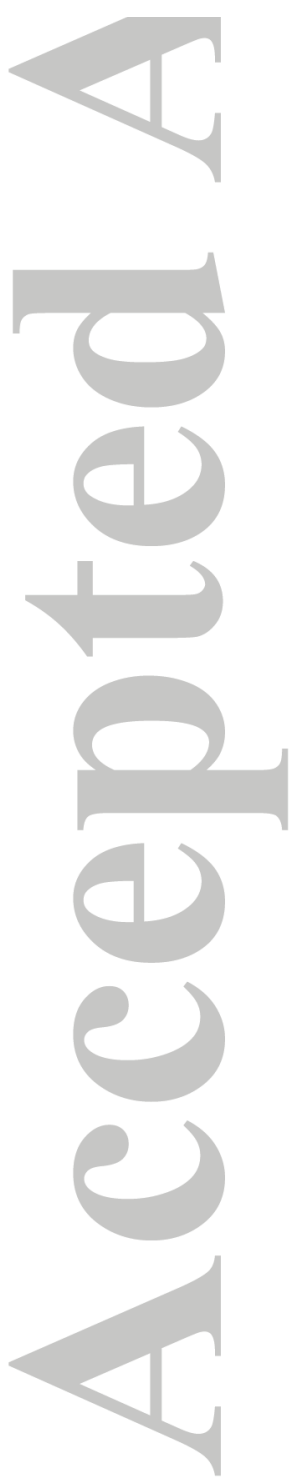


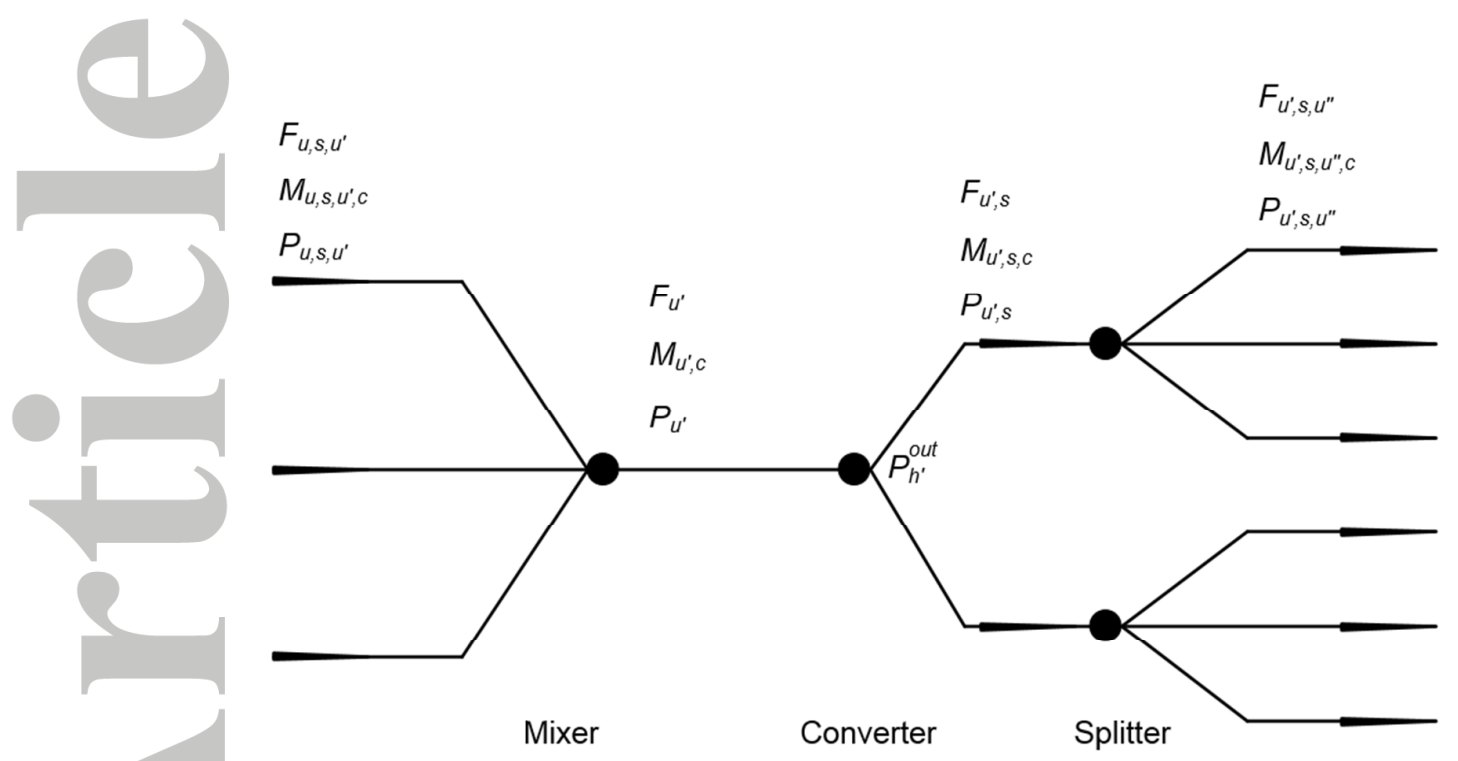

Figure 3. Nodes and stream network for a process. 


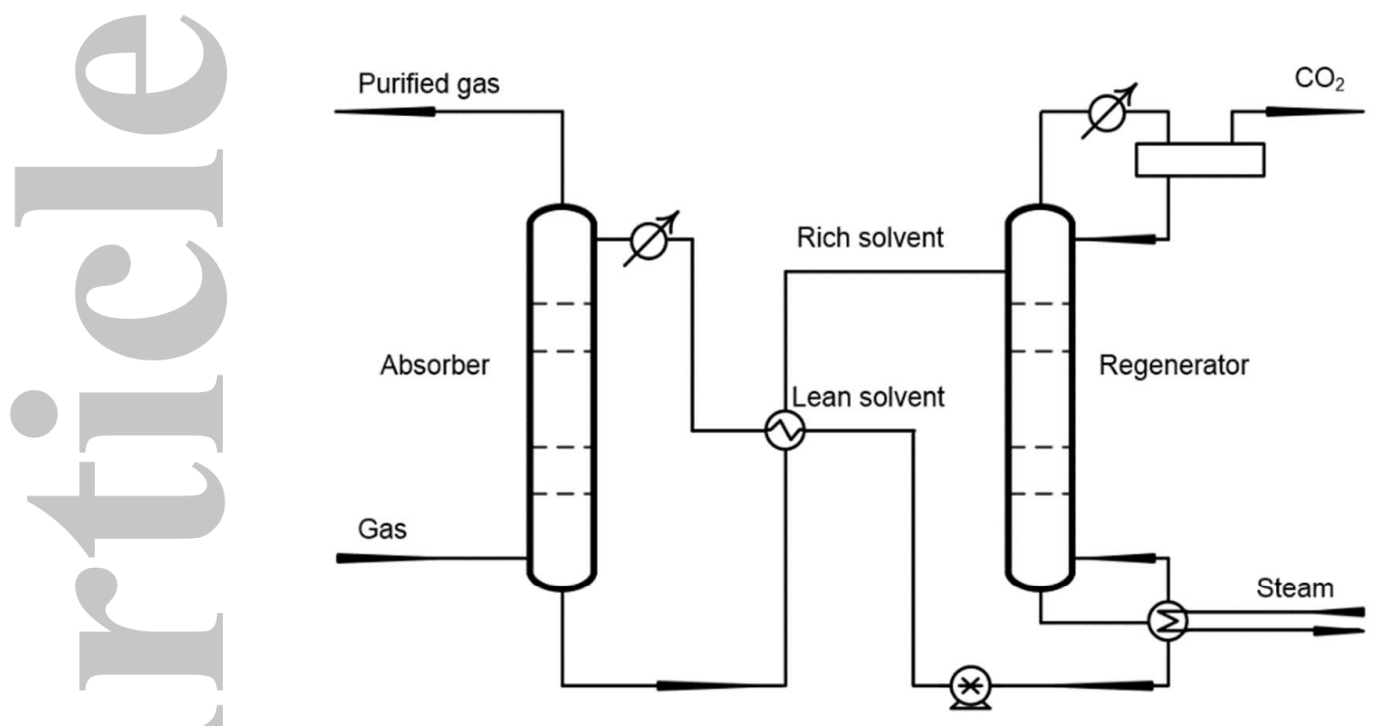

Figure 4. Schematic diagram of $\mathrm{CO}_{2}$ treating process. 


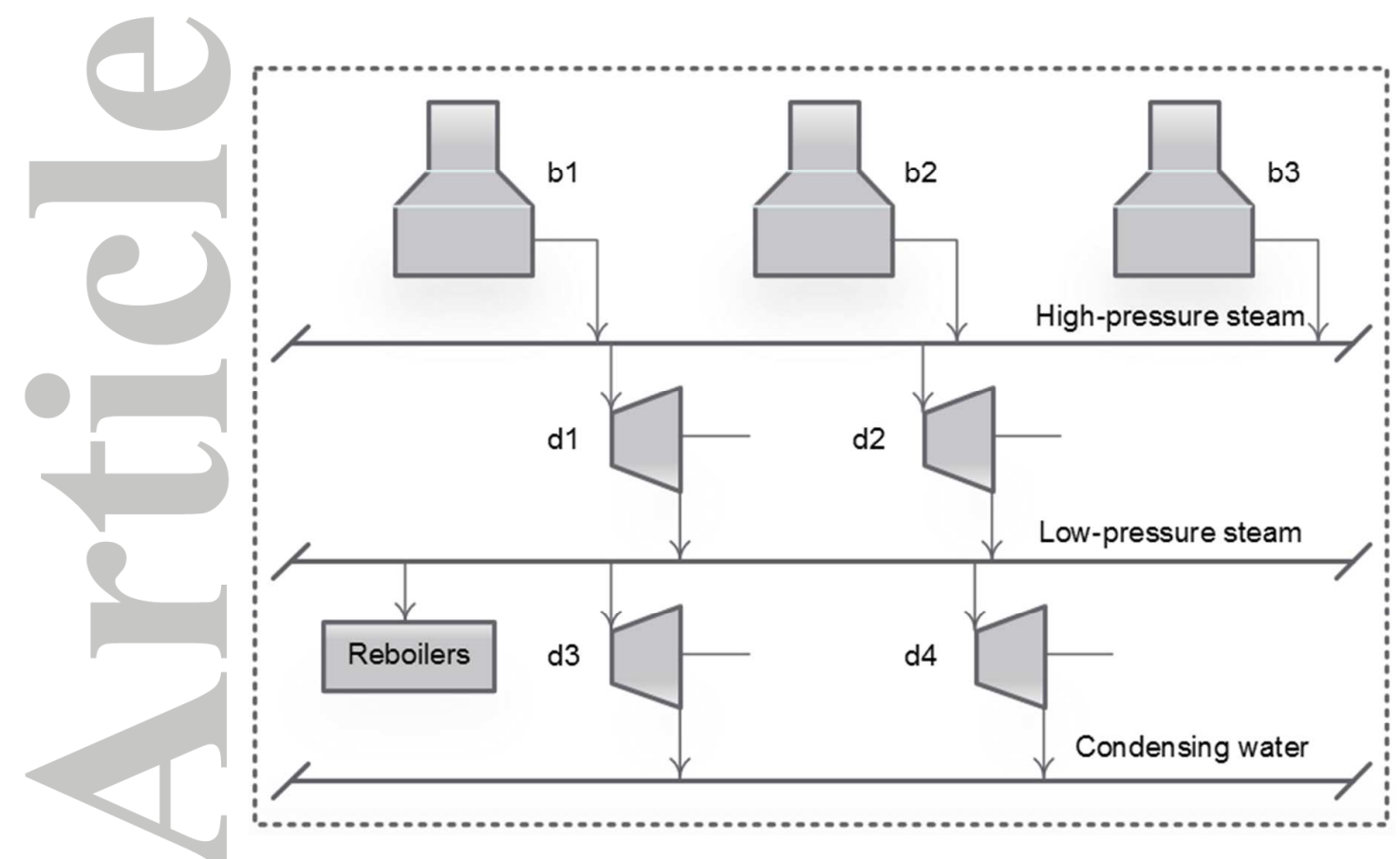

Figure 5. Schematic diagram of the utility system.

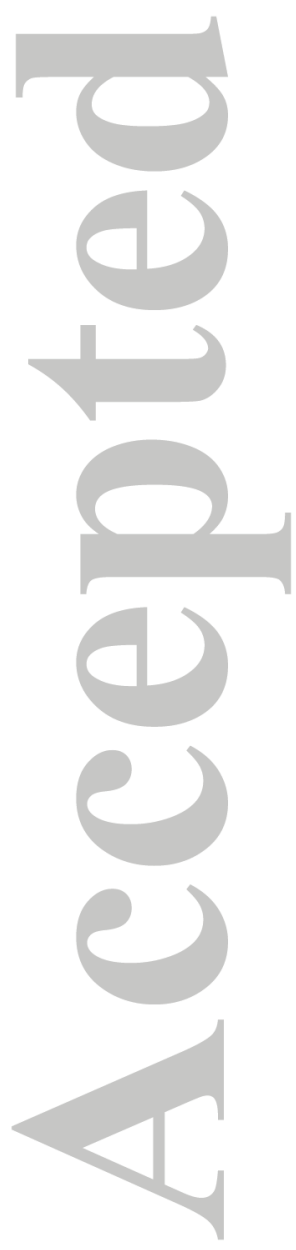




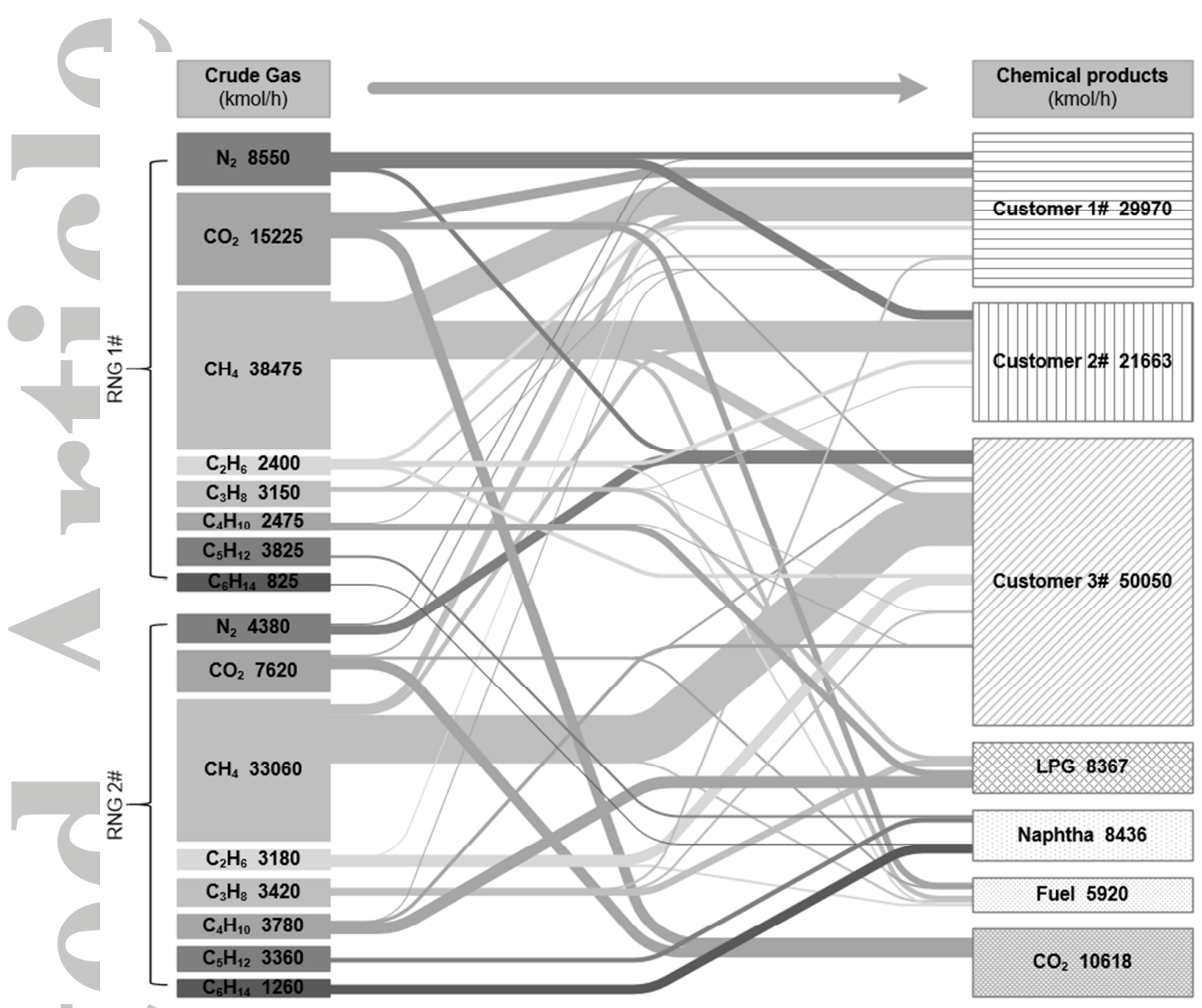

Figure 6. Best molecular flow chart from raw natural gas to products. 